\title{
Vector saliva controlled inflammatory response of the host may represent the Achilles heel during pathogen transmission
}

\author{
Claudia Demarta-Gatsi ${ }^{1,2,3,4 *}$, Salah Mécheri ${ }^{1,2,3}$ (1) \\ ${ }^{1}$ Institut Pasteur, Unité de Biologie des Interactions Hôte Parasites, Paris, France. \\ ${ }^{2}$ CNRS ERL9195, Paris, France. \\ ${ }^{3}$ INSERM U1201, Paris, France. \\ ${ }^{4}$ Medicines for Malaria Venture (MMV), Geneva, Switzerland.
}

\section{Keywords: \\ Vector saliva \\ Immunomodulation}

Parasites

Arboviruses

Vaccine

\begin{abstract}
Infection with vector-borne pathogens starts with the inoculation of these pathogens during blood feeding. In endemic regions, the population is regularly bitten by naive vectors, implicating a permanent stimulation of the immune system by the vector saliva itself (pre-immune context). Comparatively, the number of bites received by exposed individuals from non-infected vectors is much higher than the bites from infected ones. Therefore, vector saliva and the immunological response in the skin may play an important role, so far underestimated, in the establishment of anti-pathogen immunity in endemic areas. Hence, the parasite biology and the disease pathogenesis in "salivaprimed" and "saliva-unprimed" individuals must be different. This integrated view on how the pathogen evolves within the host together with vector salivary components, which are known to be endowed with a variety of pharmacological and immunological properties, must remain the focus of any investigational study dealing with vector-borne diseases. Considering this three-way partnership, the host skin (immune system), the pathogen, and the vector saliva, the approach that consists in the validation of vector saliva as a source of molecular entities with anti-disease vaccine potential has been recently a subject of active and fruitful investigation. As an example, the vaccination with maxadilan, a potent vasodilator peptide extracted from the saliva of the sand fly Lutzomyia longipalpis, was able to protect against infection with various leishmanial parasites. More interestingly, a universal mosquito saliva vaccine that may potentially protect against a range of mosquito-borne infections including malaria, dengue, Zika, chikungunya and yellow fever. In this review, we highlight the key role played by the immunobiology of vector saliva in shaping the outcome of vector-borne diseases and discuss the value of studying diseases in the light of intimate cross talk among the pathogen, the vector saliva, and the host immune mechanisms.
\end{abstract}

* Correspondence: demartagatsic@mmv.org https://doi.org/10.1590/1678-9199-JVATITD-2020-0155 Received: 16 October 2020; Accepted: 01 March 2021; Published online: 17 May 2021 


\section{Introduction}

Infectious diseases are the world's most leading cause of death among children and young adults, particularly in low-income countries. They account for 29 out the 96 underlying causes of premature death in humans listed by the World Health Organization (WHO) with roughly 4 million deaths in 2016 [1,2]. Moreover, epidemiological studies estimate that about $61 \%$ of the total number of human infectious diseases are zoonotic [3], while $75 \%$ of new diseases discovered in the last decade are zoonotic [4]. From the Greek words "zoon" = animal and "noso" $=$ disease, the zoonotic diseases are infectious diseases that can be transmitted directly or indirectly between animal species and humans. They are caused by harmful germs, including bacteria, parasites, fungi, viruses and prions [5]. Zoonotic diseases can occur via different means, directly or indirectly, by consumption of contaminated food or transmitted via numerous vectors.

Although they have been recognized for many centuries, in the last years, with increasing levels of contact between humans and wildlife, there has been a significant socioeconomic impact of zoonotic pathogens transmitted from animals to humans worldwide [6], and despite the fact that WHO recommend vaccinations for various zoonotic diseases, they remain a major public health issue worldwide. Additionally, the vector-borne diseases (VBDs), estimated at about $17 \%$ of all infectious diseases, represent a fairly good proportion of the neglected tropical diseases (NTDs) in many regions of the world, where they more severely affect the poorest and most vulnerable populations. They are causing more than 700,000 deaths annually and for the most of them there is no vaccine that allows protection, such as malaria, dengue, zika and leishmaniasis [7]. It is expected that the impact and the prevalence of these diseases will increase substantially in the future with the blooming of a wide array of mosquito species that flourish with the climate change $[8,9]$. Vectors play an active role during disease transmission, as disease courses are more severe. Accordingly, delivery of arboviruses in combination with uninfected mosquito bites causes as more severe disease as when viruses are delivered via infectious mosquito bites [10-14]. In mouse models, mosquito and sand fly saliva have also been shown to enhance infectivity and disease progression $[15,16]$. From the perspective of infectious diseases, vectors are living organisms, in addition for being themselves infected, that spread infectious agents between organisms of different species. Different populations of a vector species may not exhibit the same ability to transmit a pathogen [17-19]. Many of the vectors are bloodsucking arthropods, such as mosquitoes, ticks and sandflies, which ingest disease-producing microorganisms during a blood meal taken from an infected host (human or animal) and later inoculate it into a new host during their subsequent blood meal. In their quest for a blood meal, vectors transmit pathogens altogether with a cocktail of bioactive molecules present in their saliva into their vertebrate hosts. They can transmit infectious diseases either actively or passively: (i) certain biological vectors (e.g. mosquitoes and ticks) carry pathogens able to multiply within their bodies and are readily delivered to new hosts and (ii) mechanical vectors (e.g. flies) which pick up infectious agents on the outside of their bodies and transmit them through physical contact. Transmission depends on the vector competence and the capacity of the pathogen to cross the various barriers in the vector. These can be influenced by different parameters such as environmental factors (temperature, mosquito midgut microbiome), genetic factors (parasites and hosts), and physiological factors (hosts and parasites) $[20,21]$. Moreover, they can be influenced by the specific species of vector involved in the transmission cycle of the pathogen. In fact, in the last decades, with the increase of human movement we assisted to the spread of the main vector such as the Culicine mosquitoes responsible of different arbovirus infections, from Africa to the New World. The introduction of competent vector species and pathogenic arboviruses into new geographic regions, where immunologically naïve hosts are present, have profoundly changed the epidemiology of arboviruses. The relevance to geographic distribution is the effect of the environment on both the biology of the vectors but also the relationships between the vectors and the viruses [22].

Climatic factors that influence temperature and rainfall, either in intensity, duration or variability, greatly affect the vector population, and consequently, the pattern and level of pathogen transmission and disease propagation [23, 24]. Insects are cold-blooded or poikilothermic organisms, which cannot regulate their own temperature. Since specific body temperatures need to be reached to achieve essential biochemical reactions, the development and physiological functions of the insect is dependent upon the ambient temperature and requires a certain amount of heat to be completed [25]. In fact, at higher temperatures, the mosquito life cycle is shorter than at lower temperatures, and typically there is a species-specific lower temperature threshold at which the species cannot survive $[26,27]$. Additionally, the temperature is an important factor to determine the vector competence. In fact, it influences the kinetics of replication and dissemination of viruses and parasites in the vector [28]. Another important climate factor is the frequency and intensity of the rainfalls. It was demonstrated that the vectorial capacity is a function of vector density, which is strongly related to rainfall patterns in the case of mosquitoes [29]. In fact, it has been observed that extreme rainfall followed by floods and increased formation of rain pools have an impact on diseases transmission as these phenomena contribute to the expansion of the vector population.

Like the human saliva, which is essential for proper functioning of the human body by fulfilling numerous important functions, such as protection against microorganism or disinfection, a prominent function of vector saliva is intimately associated with pathogen transmission. The only tissue of the body where the vector and its saliva, the pathogen, and the vertebrate host immune system are present at the same moment is the skin. Therefore, the skin represents the first barrier against invading pathogens and various antigens and allergens and consists of a complex cellular network that subsequently shapes the systemic 
immune response. Hematophagy has evolved in parallel with the diversification of salivary constituents to achieve successful blood meal acquisition and to prevent skin defense mechanisms such as hemostasis, pain, itch, and immune effector mechanisms $[30,31]$. The saliva of arthropods is widely known to promote and accelerate transmission of pathogens [32, 33]. A comprehensive understanding of the importance of arthropod vector saliva can help shed light on vector-host-pathogen relationship and how these parasites overcome host defenses, revealing new molecules of potential use for control and therapeutic applications. Mosquito saliva is a complex mixture of proteins that allows the mosquito to acquire a blood meal from its host (necessary for egg maturation), by circumventing vasoconstriction, platelet aggregation, coagulation, and inflammation or hemostasis [34]. Moreover, it is well known that mosquito saliva contains proteins that are immunogenic to humans, and some allergic responses can be severe $[35,36]$. Recently, the immunomodulatory role of saliva against arboviruses [37,38] and protozoa including Leishmania [33, 39], Trypanosoma [40], and Plasmodium [16, 36] has been reported. Additionally, because mosquito saliva can be immunogenic, it is speculated it may enhance the pathogenicity by manipulating the host's immune response. The administration of pathogens with vector saliva and their delivery in the skin call for a thorough investigation of immune mechanisms occurring at this site which may influence the outcome of infection. In this review, we discuss the essential role of vector saliva in pathogen transmission, with the focus on malaria parasites, arboviruses and Leishmania and highlight the value of considering vector salivary components as possible vaccine candidates against pathogens.

\section{Pro-inflammatory and immunomodulatory properties of arthropod saliva}

The human immune system is a network of cells able to discriminate between self and non-self and to mount a response to an invading pathogen, toxin, or allergen, protecting the body against diseases. The host uses both innate (natural killer cells, neutrophils, monocytes, macrophages, mast cells, and dendritic cells) and adaptive ( $\mathrm{T}$ and $\mathrm{B}$ cells) mechanisms to detect and eliminate pathogenic microbes. Once activated, the first step of response constitutes the innate immune response. At this stage, cells produce cytokines and chemokines, which enhance the killing via cytotoxic molecules, and the pathogen phagocytosis, which facilitates pathogen elimination allowing dedicated cells to process antigens for presentation to $\mathrm{T}$ cells and subsequent $\mathrm{B}$ cell proliferation. At this point, the second step of responses that constitutes the adaptive immunity is initiated by activating and differentiating $\mathrm{T}$ and $\mathrm{B}$ cells into effector or long-lived antigen-specific memory cells. A major challenge in understanding the pathophysiology of VBDs is not only to decipher the immunobiology of the pathogen but also to characterize the immune-modulatory properties of vector salivary components.
Athropods saliva is a highly diverse mixture of proteins that can differ among different species [41, 42], among populations originating from different geographical locations [41, 43-45] and between females which feed on blood and non-blood feeding males [41]. Several of these proteins have unknown functions, that allows female arthropods to feed on mammalian hosts, by preventing vasoconstriction [46-48], inhibiting platelet aggregation [49-51], inhibiting blood coagulation cascade [49], and impairing the classical complement pathway [52]. Consequently, all these biological functions impair the capacity of the hemostatic system promoting blood feeding. Additionally, some of these salivary proteins released into the bite site are immunogenic to humans resulting occasionally in severe allergic responses [35, 36], which may facilitate the establishment of infections by manipulating the host immune system (Figure 1).

\section{Immunomodulatory effects of mosquito saliva}

Several mouse studies showed that mosquito saliva impairs the frequencies of several immune cells in different tissues promoting the development of a Th2 immune response [38]. Typically, this was the case of two key arbovirus vectors, Culex pipiens and Aedes aegypti, which had a profound $\mathrm{T}$ cell modulatory effect in a virus susceptible mouse model by down regulating and up regulating IFN- $\gamma$, and IL-4, respectively, which was not the case in the flavivirus resistant hosts [53]. Moreover, the achykinins sialokinin-I and sialokinin-II, which are present in the saliva of Aedes aegypti, mimicked the effect of mosquito feeding by modulating the host $\mathrm{T}$ cell responses in the same way [53]. This causal link is not always obvious since recent studies suggest that aggravation of infection by mosquito bites takes place earlier before the adaptive immunity in naive mice occurs, and therefore has no impact on this process. Indeed, a characteristic bite-associated severe infection was observed in severe combined immunodeficiency (SCID) mice, which lack T and B cells, whereas conventional Th1 or Th2 cytokines (e.g., IFN- $\gamma$, IL-4) were barely present after mosquito biting of naive wild-type mice in the absence of virus infection [54]. In particular, it was concluded from this study that mosquito bite facilitation of virus infection does not rely on host cutaneous IFN- $\gamma$ and does not require adaptive immunity. Rather than suppressing or subverting skin anti-viral immune responses, mosquito bites triggered IL-1 $\beta$-producing inflammatory neutrophils required for the induction of cutaneous inflammatory responses that enhanced Semliki Forest Virus infection [53].

Recently, a study involving human peripheral blood mononuclear cells (PBMCs) engrafted humanized mouse models showed that mosquito saliva affects cytokine levels, increasing anti-inflammatory cytokine production and thus promoting a Th2 immune response after one week post-bite [55]. Classically, a Th2 immune response is a characteristic of parasitic infections or allergen exposure, and tends to dampen inflammatory and cytotoxic responses, both of which are needed to clear parasitic 


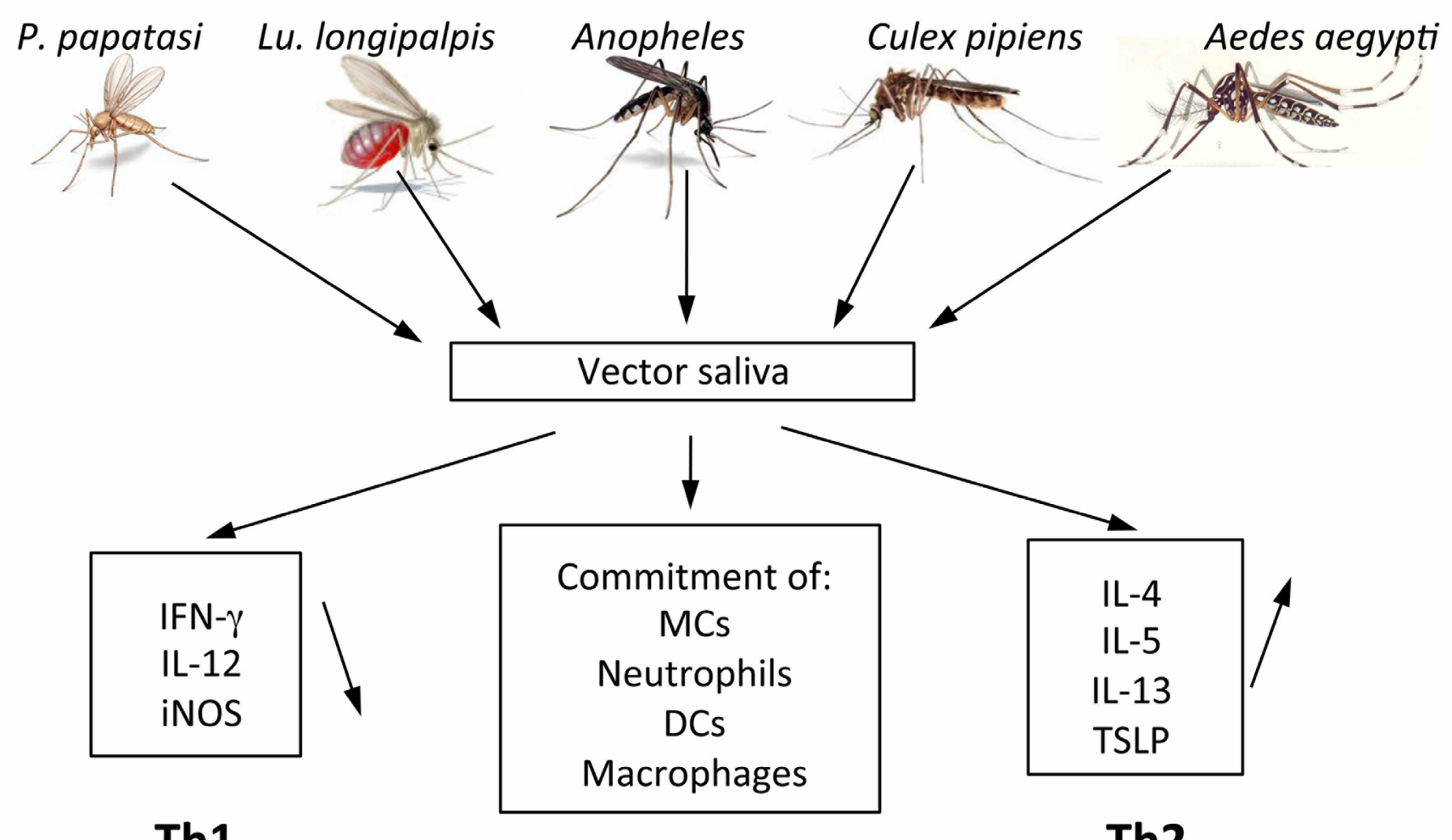

Th1

Th2

PROTECTION

DISEASE

Figure 1. Arthropod saliva has a profound effect on pathogen transmission and on the exacerbation of the disease. Saliva or salivary products from various vectors operate at different levels. They promote the development of a predominant Th2 response, shifting the host response from protection to disease, and they alter the cellular distribution and function of various leukocytes at the bite site.

or viral infections. Thus, the mosquito saliva allows the survival of parasites and viruses by triggering a Th2 response instead of a Th1 response. However, other studies pointed out that Aedes aegypti mosquito saliva can increase some subsets of immune cells typically associated with a Th1 immune response and generates both Th1 and Th2 response [56, 57] (Figure 1).

The ability of dendritic cells (DCs) to instruct the polarization of naïve T cells into Th1, Th2 or regulatory T cells is intimately associated with the signals that they receive in the peripheral tissues at the time of antigen capture. Thymic stromal lymphopoietin (TSLP), which is a master regulator of allergic inflammation in the skin [58,59], is produced by epithelial cells, keratinocytes and mast cells (MCs), and is critical in modulating DC function. Enhancement of inflammation-driven TSLP expression results in the influx of eosinophils, neutrophils, and MCs subsequent to macrophage activation, DC maturation, and induction of Th2 cells, leading to pathological expression. DC activation upon TSLP promotes the development of inflammatory Th 2 cells that produce the conventional Th 2 cytokines IL-4, IL-5, and IL-13 and high amounts of TNF- $\alpha$. During the sensitization phase of the delayed type hypersensitivity (DTH) response, DCs capture the antigen, translocate to draining lymph nodes and undergo a maturation process necessary for the activation of naive T cells. Not only MC produce TSLP, but they also secrete histamine and other inflammatory mediators that may affect DC maturation, which then fail to ultimately elicit full activation of effector T cells. Notably MCs induce the production of IL-10 via histamine [60]. IL-10 is an important regulator of the DTH response [61], limiting the associated inflammation and tissue damage [62]. Lack of IL-10 results in prolonged DTH response and, conversely, high levels dampen the DTH reaction.

IgE-dependent type I hypersensitivity is an immediate reaction, also designated atopy and allergy, includes atopic dermatitis (AD), rhinoconjunctivitis and asthma. Augmented secretion of Th2 cytokines IL-4, IL-5 and IL-13, promotes B cell class switching to IgE, leading to enhanced production of IgE in response to allergens. IgE bind to MCs and basophil via high-affinity receptors (FceRI) as well as to low-affinity receptors (FcERII/CD23) preferentially expressed on B cells, activated macrophages and eosinophils. Aggregation of receptor bound 
IgE by allergens triggers the release from MCs and basophils of histamine, leukotrienes and peptides attracting neutrophils and eosinophils. By contrast, DTH, a reaction that takes two or three days to develop, is unrelated to antibodies and is rather under the control of $\mathrm{T}$ cells and monocytes/macrophages. Peptides generated from antigens, processed by antigen-presenting cells (APCs), such as DCs and macrophages, are associated to the major histocompatibility complex (MHC II) molecules and presented to $\mathrm{CD} 4{ }^{+}$Th1 cells. APCs are activated and secrete IL-12, which stimulates the proliferation and activation of $\mathrm{CD}^{+}$Th1 cells, which produce IL- 2 and IFN $-\gamma$, inducing a further release of other Th1 cytokines, thus paving the way to the immune response. DTH is a major mechanism of defense against intracellular pathogens, such as mycobacteria, fungi, and some parasites. DTH also occurs in allergic contact dermatitis and in some autoimmune diseases including multiple sclerosis and coeliac disease.

The induction of specific IgE in response to mosquito saliva has been well documented. Saliva contains pharmacologically active proteins and peptides [32], which elicit the production of IgE and IgG antibodies $[63,64]$ and cause a localized allergic reaction in the skin, and dermal hypersensitivity reactions [65, 66]. Both immediate and delayed response in humans were shown to be elicited by Anopheles (An.) albopictus salivary gland extracts (SGE) when inoculated intradermally [67]. Mosquito bites thus result in both immediate and delayed local cutaneous reactions $[68,69]$. While these distinct hypersensitivity reactions are relevant to the immune response to saliva, recent work suggests that this response is rather complex and that MCs play a major role in these two responses.

In addition to the classical IgE-dependent activation of MCs, alternative means for MC activation exist; inflammatory responses initiated by MCs at skin sites exposed to mosquito bites were evidenced in naive mice, indicating that MCs can be directly activated in the absence of saliva-specific antibodies [70]. The mosquito bite induced a local cellular infiltrate in the skin and increased cellularity of the draining lymph nodes affecting a broad leucocyte pattern including $\mathrm{T}$ and $\mathrm{B}$ lymphocytes, DCs, neutrophils and monocytes/macrophages, in short, a conventional DTH response [70]. MCs are a source of TNF- $\alpha$ and macrophage inflammatory protein 2 (MIP-2), which are both promoting neutrophil influx and T cell-mediated DTH response $[71,72]$. In a model of contact hypersensitivity reaction, increased amounts of MIP-2 were detected only in the presence of MCs and were associated to DC migration [71, 73]. As a consequence of the induction of MIP-2 by mosquito bites, it was observed an upregulation of IL-10 in the draining lymph nodes with subsequent downregulation of T-cell mediated immune responses mediated by IL-10 [36]. Among saliva constituents that could activate skin MC, Histamine Releasing Factor (HRF), a well conserved protein expressed by all eukaryotic cells including all Plasmodium parasite species which acts both intracellularly and extracellularly, was also identified as part of salivary components (personal observation). The capacity of mosquito saliva to upregulate IL-10 expression has been documented across a range of mosquito species and appears as a key generalized immune response.

The upregulation of IL-10 expression after exposure to mosquito saliva has been observed across a range of mosquito species and is thus a key generalized immune response [36, 38]. IL-10 inhibits the synthesis of IFN- $\gamma$, IL- 2 , and TNF- $\beta$ [74], antagonizes IL-12, downregulates MHC class II expression by monocytes and inhibits antigen presentation by several APCs $[73,75]$. Enhanced IL-10 production can thus antagonize T-cell activation with clear consequences for the development of an efficient immune response against any invading pathogens [76]. IL-10 and perhaps other immunosuppressive mediators produced by MCs in response to mosquito saliva likely result in a dysregulated DTH response and subsequent ineffective antigen-specific T-cell responses. This would have a potentially significant impact on any antigen that is present at the time of saliva inoculation.

\section{Immunomodulatory effects of sand fly saliva}

Sand fly saliva has chemotactic activity on different immune cells, thereby modifying inflammatory processes at the bloodfeeding site. In animal studies, a significant macrophage influx was observed after Lutzomyia (Lu.) longipalpis salivary gland homogenate injection that was directly correlated with a higher chemokine expression of CC chemokine ligand 2/monocyte chemoattractant protein-1 (CCL2/MCP-1) in BALB/c strain but not in $\mathrm{C} 57 \mathrm{BL} / 6$ mice highlighting the importance of the host background [77]. Other studies using another sand fly, Phlebotomus (P.) papatasi, have shown the ability of its saliva to inhibit the secretion of pro-inflammatory cytokines and consequently enhance the production of anti-inflammatory cytokines, thereby dampening macrophage effector functions. In mice, the P. papatasi salivary gland lysate inhibits IL-12 and IFN- $\gamma$ expression, while the expression of IL-4, which may interfere with the development of a protective Th1 response, was up-regulated [78]. Additionally, it was shown that saliva of P. papatasi inhibits the ability of IFN- $\gamma$ to activate macrophages to produce nitric oxide (NO) facilitating parasite survival. This observation was supported by studies that highlighted the role of two small, ethanol-soluble, thermoresistant salivary molecules, 5 'AMP and adenosine, in the downregulation of the iNOS gene expression and reduction of NO production through the inhibition of protein phosphatase 1 and protein phosphatase 2A. These two phosphatases being crucial in modulating the signals that facilitate production of NO [79, 80].

The translation of these finding into humans was made possible by the study of the natural exposure to the saliva of $P$. papatasi and $L u$. longipalpis. Natural exposures resulted in increased IL-10 [81], which inhibits the proliferation of lymphocytes 
producing IFN- $\gamma$, IL-6, IL-8 and IL12p40 [82]. Moreover, human DC, neutrophils, and monocytes are affected by exposure to $\mathrm{Lu}$. longipalpis saliva, in particular it was observed that neutrophils undergo an apoptotic program in a FasL-mediated caspasedependent manner [83]. Saliva was found to alter the expression of co-stimulatory molecules in DC, macrophages, and monocytes [82] and to down-regulate the production of TNF and IL-12p40 in LPS-stimulated monocytes [82].

Interestingly, the maxadilan (MAX), a vasodilator peptide present in the saliva of the sand fly, was also able to modulate the host immune response. MAX was reported to up-regulate cytokines associated with the Th2 response (IL-10, IL-6, and TGF- $\beta$ ) and to downregulate Th1 response cytokines (IL-12p70, IFN- $\gamma$ and TNF- $\alpha$ ) and NO [84-86]. Moreover, DCs exposed to MAX showed reduced expression of co-stimulatory molecules (CD80 and CD86) and CCR7 expression and increased secretion of type 2 cytokines suggesting that MAX can act not only on the DCs phenotype, but also on their function [87]. In addition, P. papatasi and P. duboscqi salivary components were shown to inhibit DC ability to present antigens and subsequently block the immune response initiated by the activation of naïve $\mathrm{T}$ lymphocytes and their differentiation into specific subtypes [88]. Another immunomodulatory mechanism associated with the sand fly saliva was the sequential production of prostaglandin E2 (PGE2) and IL-10 by DCs resulting in the downregulation of the cell surface MHC class II and CD86 molecules [88]. Moreover, Lu. longipalpis saliva was able to induce lipid body formation and PGE2 production in peritoneal macrophages via the ERK-1/2 and PKC- $\alpha$ signaling pathways that are produced in response to inflammatory stimuli contributing to the development of an anti-inflammatory response [89].

\section{Modulation of the infection outcome by vector saliva - disease examples}

Among a wide range of insect vectors and their associated pathogens, insect saliva was found to consistently enhance pathology, and infection severity [90]. Conversely, prior exposure to non-infectious bites protects against severe infection; repeated exposure to non-infectious bites eventually results in the elicitation of a Th1 response to salivary antigens and in parallel to the pathogen $[91,92]$. Creation of a Th1 biased environment rather than a Th2 biased one is apparently critical in dictating the outcome of a subsequent infection [93]. Thus, saliva could be critical in orienting the immune response mounted against involved parasites.

\section{Saliva of Plasmodium parasite-transmitting vectors}

Despite the efforts made, malaria, unfortunately, remains one of the greatest burden of humanity today and is the third leading cause of death among infectious diseases after HIV and tuberculosis. Malaria is caused by protozoan parasites belonging to the genus Plasmodium that infects humans, birds, reptiles, and other mammals through the intermediary of an infected female Anopheles mosquito. Each year around 3.4 billion people, or almost half of the world's population, are exposed to malaria risk, mainly in the intertropical zone [94]. Africa is the continent mostly affected globally, with nearly $90 \%$ of deaths, mainly in the sub-Saharan zone where climatic conditions are particularly favorable to the development of $A n$. mosquitoes $[95,96]$. However, malaria is not limited to Africa. It also occurs in the tropical and subtropical Asia and Latin America. Recently, despite the numerous efforts to eliminate and eradicate malaria, we must face the increase in resistance phenomena associated with synthetic antimalarial compounds [97, 98] and the use of insecticides [99]. Under these conditions, identification and functional characterization of parasite, vector and host key proteins involved in this multi-system disorder are a major challenge of the post-genomic era of Plasmodium research.

The main factors related to the intensity of malaria transmission are population density, longevity, behavior and vector efficiency. The vectors responsible for the transmission of human malaria are arthropods belonging to the subfamily of Anophelinae [100] and to the genus of Anopheles [101]. Each species of Anopheles occupies a geographical area. More than 484 species belonging in the genus Anopheles have been identified [102] of which only about sixty ensure with efficiency, the transmission of human plasmodia. Moreover, they can modify their biting and resting behaviors in evolutionary response to the presence of insecticide-treated mosquito nets, indoor application of residual insecticides, or the absence of preferential host in one location $[103,104]$. Human malaria infection starts when a female anopheline inoculates the Plasmodium parasites into the skin where it encounters the first line of defense of the human body. Increasing evidence from mouse models to natural infections in human populations provide support for considering the immune response to malaria within an allergic context. Saliva and its allergenic nature through direct response by immune effectors in the skin have significant immediate and long-term effects for the outcome of infection by malaria parasites and the development of clinical immunity [105].

It is recognized that the type of the innate immune response developed at the site of sporozoite inoculation plays a significant role in containing Plasmodium infection. In malaria mouse models, it was shown that natural mosquito feeding leads to elevated parasitemia and the increase of more severe forms of malaria. These effects occur following deregulation of immune signalling and a reduction in the recruitment of key inflammatory cells into the inoculation site [106]. This deregulation may be associated with the crucial antiparasitic role played by DCs in cutaneous draining lymph nodes where the first wave of the anti-sporozoite effector $\mathrm{CD}^{+}{ }^{+}$T-cells is triggered by DCs after an infectious mosquito bite [107]. Additionally, another key factor is the balance between anti and pro-inflammatory cytokines. In fact, during pathogen infection, early cytokines responses involving IL-4 and IL-10 increase host susceptibility, whereas responses involving IL-12 and IFN- $\gamma$ are important for resistance. The immunosuppressive role of IL-10, upregulated by 
saliva, was shown to exacerbate the infection and disease; early IL-10 expression was associated with increased T regulatory cell proliferation, suppression of Th1 cytokines, as well as the increase of the parasitemia and mortality [108]. In conclusion, both the Type 1 hypersensitivity response, as suggested by IL- 4 expression plus the defective Type 4 hypersensitivity response abrogated by IL-10 contribute to increased infection severity and compromise the development of an effective immune response. The immunomodulation of the Type 1 and Type 4 hypersensitivity responses by mosquito saliva creates an immunological environment that hastens disease development with subsequent dysfunction of the host immune system. Mouse model studies have revealed much about the immunomodulatory role of saliva and its impact on the outcome of malaria parasite infection. Interestingly, despite using different species of mosquitoes and different parasite species, there are consistent effects suggesting that there exist generalizable phenomena potentially pertinent to human malaria. Extending from mouse models to natural infections in humans living in malaria endemic settings is a necessary but challenging step.

The complement system is known to act as a vital component of the immune response against invading pathogens. As an example, $\mathrm{Clq}$ interacts with its receptors expressed on neutrophils and phagocytic cells and activates these phagocytes to produce reactive oxygen species to attack pathogens. Saliva of Anopheline mosquitoes and other arthropods contains anti-hemostatic and immune-modulator molecules, among which Complement inhibitors, that favor blood feeding and parasite transmission [109]. Considering the presence of complement inhibitors and other immunomodulatory molecules in arthropod's saliva, multiple pathogens could benefit from their depressant action during transmission by the vectors. In this regard, two proteins belonging to the SG7 family that are capable of inhibiting the alternative pathway have been described [110]. Complement inhibitors not only facilitate blood feeding of vector arthropods but in addition, they represent an effective strategy that parasites utilize to survive in the host. Indeed, Plasmodium falciparum parasites express various proteins, among which C1-INH, that effectively play these roles [111].

Following the seasonal expansion of the mosquito population with the rains, mosquito bites were found to be strongly positively associated with an increase in parasite density in chronic pre-existing asymptomatic infections [112-115]. Additionally, individual anti-mosquito SGE IgE titers were also found to be strongly positively correlated with anti-parasite IgE titers. This is consistent with the hypothesis that mosquito bites predispose individuals to develop an IgE anti-parasite response, potentially by the orientation of the immune response to a Th2 profile [53]. Such an orientation of the immune response may lead to a reduced Th1 type response resulting in a lower acquisition of asexual parasite-targeting defense mechanisms and thus a more fertile ground for asexual parasite survival. These observations suggest that the mosquito saliva is responsible for an imbalance in the host Th1/Th2 response by inducing an
IgE response and a dysfunctional Th1 response. Such a Th1/Th2 imbalance is characteristic of atopy and thus atopic individuals might be expected to respond differentially to mosquito bites, parasitic infection and the immune-modulatory role of saliva. Orientation of the immune response towards a Th2 profile by allergic diseases - such as asthma or AD - would result in a poor Th1 response and thus amplify the effects of saliva and hence the immunological response to infection.

In a birth cohort of children living in malaria endemic settings, there was an association of asthma and AD with susceptibility to clinical Plasmodium falciparum episodes [116]. In particular, children with clinically defined asthma and especially AD showed an allergy-associated risk of malaria with higher parasite burden during symptomatic episodes, suggesting a reduced ability to contain parasite growth and impaired development of acquired immunity that may stem from their imbalanced Th1/Th2 response. Interestingly, only mosquito saliva, a known major local allergen, was found to be a significant risk factor of $\mathrm{AD}$, inducing a specific IgE response at significantly higher titers in individuals with $\mathrm{AD}$. Considering the strong positive correlation between saliva and parasite IgE titers, this result strongly suggests that a Th2 environment is indeed impairing control of the parasite and undermining the development of anti-parasite immunity.

In conclusion, the early response of sentinel cells, such as DCs and MCs, determines the evolution of the immune response. Saliva provokes a localized allergic reaction in the skin and induces the production of IgE and IgG antibodies. DCs that are primed by saliva to elicit a Th2 phenotype are more susceptible to orienting the immune response toward a Th2 profile when confronted to a bystander antigen. The orientation of the immune response toward a Th1 profile is crucial for immunity to intracellular pathogens, whereas orientation toward a Th2 profile drives immunity to extracellular pathogens and antigens, resulting in class switching, giving rise to IgE-producing $B$ cells. Anti-saliva IgE titers were found to be strongly associated with the occurrence of atopic dermatitis, which was found to reduce the rate of development of clinical immunity in a birth cohort study. Thus, an atopic Th2 terrain, exacerbated by mosquito bites, influences the course of a single parasite infection and the long-term ability to develop immunity against the parasite.

\section{Saliva of arbovirus-transmitting vectors}

The term arbovirus, from the acronym arthropod and borne, includes several families of viruses transmitted to humans by arthropods such as mosquitoes and ticks. All arboviruses have a common feature, an RNA genome that allows them to rapidly adapt to ever-changing host and environmental conditions. The families of viruses, in the current classification, included in the arbovirus group are Flaviviridae, Togaviridae, Bunyaviridae, and Reoviridae [117]. Arboviruses include more than 250 species with ubiquitous distribution, of which at least 80 cause pathologies in humans. Birds are often reservoirs for arboviruses, which are then passed on to horses, other pets, and humans by mosquitoes. 
These viruses can be transmitted directly to humans from non-human reservoirs, but interhuman transmission can also occur. Most arbovirus diseases are not transmitted by humans, perhaps because typical viremia is inadequate for infecting the arthropod vector, with some exceptions like dengue fever, yellow fever, zika virus infection and chikungunya disease which can be transmitted from person to person by means of mosquitoes [118]. Transmission efficiency depends on how potent the virus traverse the multiple barriers in the vector and the different interactions among vertebrate hosts, vectors, and viruses that can occur on multiple levels and impact transmission patterns and disease pathogenesis [22].

The early events of arbovirus infections are important for the survival of the host, with a close relationship between early peripheral virus burden and mortality [119]. The chance of onward transmission and its ability to cause more pronounced disease is increased during natural infection by mosquitoes. Different studies using mouse models showed that mosquito bitetransmitted arboviruses, or viruses accompanied experimentally by mosquito saliva or SGEs, induce more rapid viremia, higher pathogen load, and greater morbidity compared to needle inoculation in the absence of mosquito-derived factors $[13,54$, 120-122]. In fact, it was demonstrated that the intradermal inoculation of the Rift Valley fever (RVF) virus in C57BL/6 mice along with mosquito saliva and SGE increased the mortality rates of mice, as well as the virus titers measured in several organs and in the blood [121].

More recently, using a mouse model, it was shown that rather than eliciting anti-viral immune responses, mosquito bites triggered a leukocyte influx that facilitated infection by providing new cellular targets for infection [54]. A two-step process was identified; an influx of cutaneous inflammatory neutrophils caused by mosquito bites appeared to be essential for the initiation of the innate immune responses to pave the way for the chemokine receptor CCR2-dependent entry of myeloid cells that are permissive to viral infection. Therapeutic blockade of caspase-1 and neutrophil depletion, the key components of the inflammatory response to the bite, reduced leukocyte influx, suppressed viral replication, and increased host survival. Moreover, in the absence of CCR2-mediated inflammatory myeloid cell recruitment, bites were unable to promote virus infection.

It is well established that mice deficient in IFN- $\alpha / \beta$ receptor $\left(\right.$ Ifnar $\left.^{-1}\right)$ - that are susceptible to intradermal dengue virus (DENV) infection [123] because of the inability of DENV proteins to interfere with IFN signalling in mice - display characteristic features of human disease, such as lethal vascular discharge, and thus are recognized as a model to study dengue pathogenesis. Using this model, it has been established that only inoculation of DENV in the presence of SGE of a female Ae. aegypti mosquito was able to exacerbate dengue pathogenesis, and viral infection of dermal macrophages and DCs, and amplified neutrophil and monocyte influx to the inoculated skin site. Moreover, SGE was found to contribute to systemic dengue pathogenesis, by disrupting the endothelial barrier function. More interestingly, the removal of the skin site $4 \mathrm{~h}$ post-inoculation of the virus alone rescued mice from developing severe disease, while no rescue was observed when SGE was present. These data underline the essential role of mosquito-derived products in the rapid spreading of the virus beyond the skin and in enhancing the disease severity [124].

Disease pathogenesis promoting capacity of Arthropod saliva was also observed in humans. The innate immune system represents the first barrier against inoculated flaviviruses such as DENV in the skin. A family of pattern recognition receptors (PRRs) including toll like receptors (TLRs), retinoic-acidinducible gene I (RIG-I), melanoma differentiation-associated gene 5 (MDA5), and protein kinase $\mathrm{R}$ (PKR) were found to be induced during DENV infection [125]. Replication of this virus in cultured human keratinocytes was found to be enhanced by Aedes aegypti salivary proteins [125] by inhibiting the secretion of antimicrobial peptides (AMPs), S100A7, Elafin, as well as IFNs in the earliest stages of infection [126]. In a more recent study, in contrast to keratinocytes infected with DENV alone, a significant increase in the expression of DENV transcripts was observed in keratinocytes infected with DENV in the presence of salivary proteins, among which the $34-\mathrm{kD}$ a protein. This was associated with a strong suppressive effect on the interferon regulatory factors (IRF3 and IRF7), resulting in the abrogation of type I IFN production. The authors proposed that the identification of the 34-kDa protein in Aedes aegypti saliva could serve as a target for the control of DENV replication in vertebrate hosts [127].

\section{Saliva of Leishmania-transmitting vectors}

Leishmania diseases are a group of human zoonotic VBDs caused by an intracellular protozoan parasite of the genus Leishmania and inoculated to humans by infectious bites of a female sand fly, essentially of the genera Phlebotomus for Old World and Lutzomyia for the New World. Leishmaniasis is one of the top three NTDs caused by protozoa representing a serious world health problem with a broad spectrum of clinical manifestations of infection ranging from cutaneous ulcers to a visceral form, with a potentially fatal outcome [128, 129]. The severity of clinical features depend on the species of Leishmania involved and on the immune response developed by the host. Worldwide, 1.5 to 2 million new cases occur each year, 350 million are at risk of acquiring the disease, and leishmaniasis causes 70,000 deaths per year [130].

In the past years, a consistent progress in diagnostic and therapeutic approaches has significantly affected the management of leishmaniasis. However, leishmaniasis mortality and morbidity sill show an increasing trend worldwide. One of the reasons for that is the large variety of vectors that can transmit the parasites. All the 20 recognized Leishmania species that are pathogenic for humans can be transmitted by 100 out of the 900 different species of sand fly recorded [131, 132]. Additionally, it was observed that the phlebotominae potentially implicated in Leishmania transmission belong to 13 genera at least [133, 
134], assessing the importance of the vector in the endemic setting. As mentioned before, infected vector females feed on mammalian hosts and regurgitate parasites together with the salivary proteins into the bite site and release different proteins endowed with immunomodulatory properties, which facilitate the establishment of the infection.

The above-mentioned effects of sand fly saliva on the host's immune systems results in an altered environment at the feeding site that favors the development of Leishmania disease in the infected host. Parasite growth enhancement was demonstrated in various inbred strains of mice with variable susceptibility to Leishmania infection. In fact, it was shown that the chemotactic effect of saliva, responsible for the increase in the influx of neutrophils and macrophages at the blood-feeding site, is more pronounced when Leishmania parasites are co-injected with sand fly salivary molecules [77]. This resultsd in an exacerbated disease reflected by a larger ulcer that developed into a necrotic lesion compared to the mice receiving the parasite alone $[33,135$, 136]. Additionally, co-inoculation of $P$. papatasi saliva with $L$. major converted the naturally resistant C57BL/6 mouse strain into a non-healing phenotype associated with an early increase in Th2-related cytokines such as IL-4 and IL-5 [33]. Moreover, the same co-inoculation in CBA mouse strain is responsible of an upregulated expression of IL-4 and a reduced production of IFN- $\gamma$, IL-12, and iNOS [78], resulting in the promotion parasite proliferation inside the host. Following these observations, a series of in vitro studies aiming to explore the mechanisms responsible for the parasite growth in the presence of sand-fly salivary molecules were performed.

Co-inoculation of L. amazonensis with $L u$. longipalpis saliva was associated with elevated IL-10 production, leading to the suppression of effector functions of monocytes and macrophages [137]. This observation was confirmed in in vivo studies following exposure of mice to $L u$. longipalpis infected sand fly bites [138], and during stimulation of the peritoneal cavity with $L$. major plus Lu. longipalpis saliva [139], in both of which IL-10 production was observed. Additionally, neutrophils play an important role, as the first-recruited host cells to the feeding site, for the parasite survival in the vertebrate host. In fact, they act as a "reservoir" able to protect the promastigotes from a rapid degradation by cytotoxic activity of natural killer cells, neutrophils, and eosinophils in the vertebrate host before they invade macrophages [140]. Moreover, neutrophils incubated with $L$. chagasi and sand flay saliva produced significantly higher amounts of MCP-1 (CCL2) that attracts macrophages for the clearance of these recruited infected neutrophils [83, 141]. Importantly, MAX, mentioned above, was able alone to exacerbate L. major infection [142] due to its capacity to upregulate IL-10 and TGF- $\beta$ production and to suppress IL-12p40, TNF, and NO production [86]. Similar results were observed with other Leishmania-sand fly combinations, such as Lu. Longipalpis-L. braziliensis [143], Lu. longipalpis-L. amazonensis [135], Lu. longipalpis-L. chagasi [43], Lu. longipalpis-L. mexicana [143], and
Lu. whitmani-L. braziliensis [144] and P. duboscqi-L. major [145]. More important is that the enhancing effect is unique to sand fly saliva since saliva from An. aegypti, Rhodnius prolixus, or Ixodes scapularis did not enhance L. major infectivity in mice [136].

\section{Vector salivary components as vaccine candidates against pathogens}

New interventions, such as drugs and insecticide-treated bed nets became available over the last decades to reduce the burden of infectious diseases. Recently, this progress has been halted due to vector resistance and the emergence of pathogen resistance to treatments. Therefore, it is important to develop new strategies to control and eliminate the zoonotic infectious diseases. Vaccines are among the main defenses against infectious diseases, such as tick-borne encephalitis virus, Japanese encephalitis virus, and YFV. However, the development of effective vaccines is not always successful. One of the most trivial examples is the history of malaria vaccine development where the most established vaccine (RTS,S), a recombinant protein containing regions of the Plasmodium circumsporozoite protein (CSP) and targeting the sporozoites stage of the parasite confers less than $40 \%$ of protection [146, 147].

Given the complexity of the infectious agent's interactions with the host immune system, vector-based vaccine approaches may offer a solution to control VBD by taking advantage of a common variable the vector saliva. The importance of vector saliva proteins to promote the infectivity of the pathogens carried in the saliva and the establishment of systemic infection can be exploited in a novel vaccine approach through vaccination with arthropod saliva, such as saliva from ticks, sand flies, or mosquitos, conceivably preventing the infection by creating an immune environment that blocks transmission or destroys the pathogen (Figure 2).

Moreover, by targeting the vector-pathogen-host interface, one can bypass in vivo disease-specific manifestations as the vector-based vaccine acts very early at the site of the vector bite in the skin, pre-empting or complementing host antipathogen immune responses. In support of this type of vaccine, several studies have demonstrated their efficacy. Studies on the phlebotomine sand fly Lutzomyia are more advanced than those dealing with mosquitoes, as more detailed biochemical characterization of salivary components is available. As a consequence, the first studies aimed to test the capacity of the immune response to salivary proteins to protect humans were performed in leishmaniasis field as saliva component of the sand fly Lutzomyia is more extensively characterized than other vector-borne saliva. It was initially shown that parasite transmission is more effective in naïve mice than in mice previously exposed to non-infectious bites which developed a strong DTH response with IFN- $\gamma$ production at the site of parasite inoculation conferring a protective response against Leishmania major, suggesting that it is possible to develop a vaccination strategy against saliva proteins [91]. 


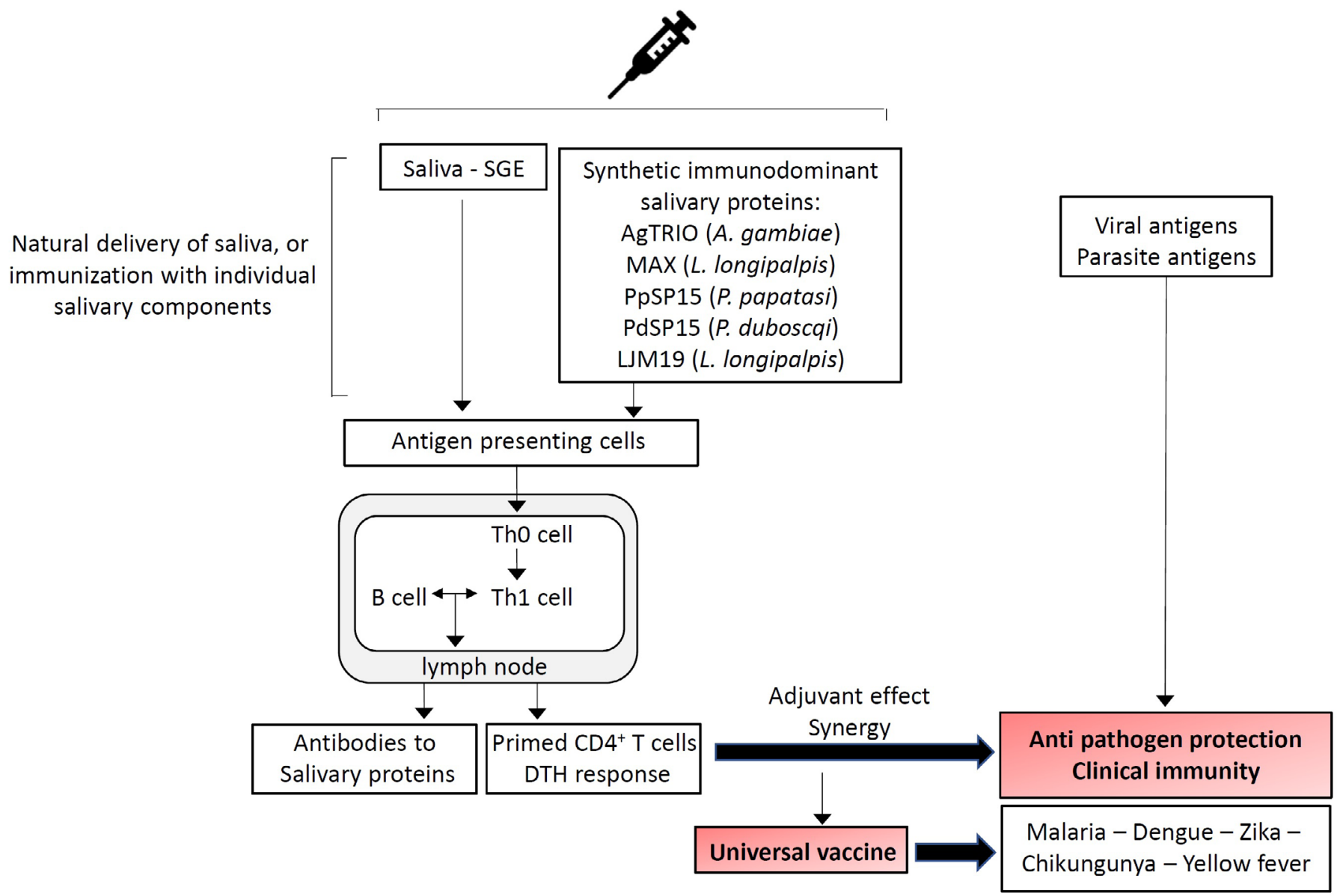

Figure 2. Mosquito and sand fly saliva-based vaccines: proposed mechanism of action. Exposure of the vertebrate hosts to saliva collected from salivary glands or to purified salivary components have the capacity to prime the immune system by eliciting antibodies to salivary components or to induce a delayed type hypersensitivity response (DTH). When the host is exposed to parasite or viral antigens delivered via infectious vector bites, vector saliva may generate an adjuvant effect in the skin for the priming of an anti-pathogen Th1 immune response necessary for protection. The saliva-based vaccine is able to elicit an increase of both anti-saliva and anti-pathogen lgG antibodies and cellular (specific CD4 ${ }^{+}$and $C D 8^{+}$cells) immune responses, resulting in a reduction of pathogen load in the immunized individuals. For vector-borne arboviruses for example, this may lead to a "universal" vaccine derived from mosquito saliva that could be a solution to offer some protection in the emerging setting of an arboviral epidemic.

Furthermore, different preclinical studies of infection on different animal species offer a proof-of-concept to the vaccine strategy using vector salivary components. Recently, Oliveira at al. identified PdSP15, a salivary protein responsible of the protective effect, by reverse antigen screening of $P$. duboscqi sand fly salivary molecules in saliva-exposed non-human primates [148]. They showed that immunization of rhesus macaques intradermally with PdSP15 DNA and boosted few days later with recombinant PdSP15 (rPdSP15) prevents cutaneous leishmaniasis transmitted by Leishmania major infected sand flies. The study demonstrated a correlation between a Th1 cell-mediated immune response and protection with cutaneous appearance of salivaspecific CD4 ${ }^{+}$IFN- $\gamma^{+}$cells within the DTH site that generates an early Leishmania-specific immune response contributing to parasite killing in the dermis and primed specific immunity to the parasite (Figure 2). This can explain the parasite protection acquired after exposure to non-infectious bites. In this case the vector saliva may generate an adjuvant effect in the skin for the priming of a Th1 anti-parasite immune response necessary for protection. The authors also provided evidence that protection mediated by anti-PdSP15-specific immune response was cellmediated and antibody-independent.

Additionally, the high homology of the protein between Leishmania vectors suggests that PdSP15 may protect against disease transmission in various areas in the world and the possible development of a universal vaccine. This crossprotection was confirmed when mice exposed to P. papatasi were subsequently infected with $P$. duboscqi SGE plus L. major [149]. The translational relevance of the study was demonstrated by testing the immunogenic capacity of rPdSP15 in endemic area. Sera and PBMCs cells from individuals naturally exposed to $P$. duboscqi bites recognized PdSP15, demonstrating its immunogenicity in humans. Moreover, PdSP15 sequence and structure show no homology to mammalian proteins, further demonstrating its potential as a component of a vaccine for human leishmaniasis. Similarly, immunity to Lu. longipalpis 
saliva LJM19 protein in hamster and to different sand fly salivary proteins in beagles protects against visceral leishmaniasis (VL), underlining the protective role of a Th1 response against the infection and confirming the protective role of salivary proteins against both cutaneous and visceral leishmaniasis $[150,151]$. Another study showed that mice vaccinated with the Lu. longipalpis salivary component MAX, responsible of the vasodilatation and immunosuppressive and antiinflammatory effects, developed both cellular responses and antibodies against the salivary protein protecting against the infection. Furthermore, in the case of disease transmission by Lu. longipalpis, MAX was thought to be the major exacerbative element since vaccinating against this molecule neutralized the effects of whole saliva [142].

Recently, a study trying to generate a more affordable and easily manufactured anti-leishmaniosis vaccine demonstrated that the synthetic full length MAX molecule as well as $\mathrm{C}$ and $\mathrm{N}$ terminal peptides derived thereof can be utilized successfully as antigens in a cationic lipid DNA complex (CLDC) adjuvant vaccine system protecting three different strains of mice (BALB/c, $\mathrm{C} 3 \mathrm{H}$ and $\mathrm{C} 57 \mathrm{BL} / 6$ ) against footpad challenges with Leishmania major co-injected with MAX. In the protected mice the immune response was characterized by an increase of IFN $\gamma$ and a decrease of IL-4 secretion from $\mathrm{CD} 4^{+}$cells in footpad-draining lymph nodes [152]. This suggests an increased Th1-bias that is potentially capable of protecting against intracellular L. major infection. These different studies demonstrated that immunity to salivary component may prevent the reprograming of innate immune responses permitting a more protective host cellular response against parasite transmission, growth, and persistence. This may lead to think that the combination of various Leishmania spp. antigens and salivary proteins could provide the best components for an efficacious vaccine.

Different possible combinations of sand fly saliva or salivary proteins with Leishmania antigens or attenuated Leishmania parasites were tested demonstrating their effectiveness. The LBSapSal vaccine, proposed as an alternative approach for interrupting the domestic cycle of Leishmania infantum, was tested in dogs with the intention of protecting against canine visceral leishmaniasis. Composed of Leishmania braziliensis antigens adjuvanted with saponin and Lutzomya longipalpis SGE, the vaccine was able to elicit an increase in both antisaliva and anti-Leishmania IgG antibodies and cellular (specific circulating $\mathrm{CD} 8^{+}$cells) immune responses resulting in a reduction of splenic parasite load in the immunized groups [153]. Other studies highlighted the fact that vaccine combinations were protective only when animals were first primed with DNA sequence of the salivary protein and then boosted with the vaccine combination. This was first observed when mice primed with the sand fly salivary protein PpSP15 DNA and then boosted with a combination of PpSP15 and live non-pathogenic $L$. tarentolae expressing the cysteine proteases (type I and II, $\mathrm{CPA} / \mathrm{CPB}$ ) displayed better immunity and protection against cutaneous leishmaniasis compared to animals vaccinated with
PpSP15 or with the attenuated L. tarentolae parasites alone [154]. This result was confirmed by another study where animals vaccinated simultaneously with the Leishmania antigen KMP11 and the salivary protein LJM19 showed no improvement in the protective efficacy over the KMP11 or LJM19 vaccines alone [155]. Leishmania vaccine development is advancing in preclinical trials, with at least 3 promising candidates, considering the natural transmission of the parasite and the priming of animal models with sand fly bites before vaccination able to boost the Th1 response [156].

In the malaria field, it was recently demonstrated that the hyperimmune antisera prepared against An. gambiae SGE partly protected mice from mosquito-transmitted Plasmodium, with a decrease of early hepatic stage infection and lower levels of parasitemia when exposed to infected mosquitoes. Using DNA yeast surface display library, they identified the antigens recognized by SGE antiserum that contributed to the diminished levels of Plasmodium infection. The screen identified the An. gambiae TRIO (AgTRIO) protein, expressed only in salivary gland and not in other organs, with putative signal sequences, suggesting that it is secreted into saliva. Moreover, it was demonstrated that the presence of Plasmodium berghei sporozoites in the salivary glands increase the AgTRIO expression $[157,158]$ and production, and that its depletion does not alter mosquito probing time and blood-feeding behaviour [159]. The protective effect of antibodies against AgTRIO was tested in naïve mice that received AgTRIO antiserum and were challenged with Plasmodium berghei-infected An. gambiae mosquitoes. The administration of AgTRIO antiserum resulted in a decrease in the parasite burden in the liver and blood stage parasite levels, suggesting that Plasmodium sporozoites are directly or indirectly affected by AgTRIO antibodies and are unable to establish a high level of hepatic infection.

More interestingly, the same study was performed in FRG human liver chimeric mice, which support liver stage infection with Plasmodium falciparum $[160,161]$ and seven days after blood meal with Plasmodium falciparum-infected An. gambiae or An. stephensi mosquitoes, mice who received the AgTRIO antiserum had reduced infection levels compared with the control groups. The study showed that the AgTRIO antiserum diminished the movement of sporozoites in the murine dermis. As the number and the viability of sporozoites that reach the liver is an important factor for the disease development, any impact on this process can greatly alter the initial pathogen burden during systemic infection. In contrast to what was previously shown where exposure to mosquito bites did not protect against malaria infection $[162,163]$, which could be attributed to several factors, starting from the quantity of saliva inoculated to the host [81] or the short duration of a mosquito bite [162]. It is well known that under natural conditions, some salivary components of mosquitoes induce an antibody response in humans [164-167]. In the study mentioned before, it was shown that individuals or mice exposed to bites of An. gambiae presented low IgG responses to AgTRIO, suggesting a natural 
lack of immunogenicity following mosquito exposure, which allows a severe disease to occur. Finally, the study highlighted the ability of AgTRIO antibodies to enhance the efficacy of CSP antibodies against malaria, suggesting a synergistic efficacy of anti-CSP antibodies and antibodies to salivary components in controlling the infection.

Despite the fact that host immune responses to vector bites may be highly variable in endemic areas, given an individual's lifelong exposure to certain mosquito species and parasites or viruses they carry, salivary molecules constitute a unique link between a variety of different VBDs [168-170]. For this reason, with the increase of emerging arbovirus infections and the nonavailability of an effective vaccine during the epidemic period, the development of a "universal" vaccine derived from mosquito saliva could be a solution to offer some protection in the emerging setting of an arboviral epidemic (Figure 2). Recently, the AGS-v vaccine, a mosquito-borne disease vaccine which rather than targeting specific pathogens, elicits an immune response to four salivary peptides isolated from An. gambiae salivary glands, that are shared by several mosquitoes. Hence, the vaccine could potentially protect against numerous mosquito-borne infections including malaria, dengue, zika, chikungunya and yellow fever (Figure 2). Thus the vaccine is the only universal mosquito-borne disease vaccine in Phase I clinical trial in healthy volunteers living in non-endemic areas [171].

\section{Conclusions}

Mosquitoes and other vectors and the diseases they transmit are of growing public health concern. Often, there are no prophylaxis for these diseases other than vector control measures and no cure other than palliative care. Understanding how vector saliva interacts with the human immune system not only helps to understand the mechanisms of the disease pathogenesis but also could provide therapeutic solutions. The shift in the paradigm that vector saliva is more than simply a vehicle for pathogen transmission but rather a fluid endowed with a determining capacity in terms of pathogen virulence has opened new opportunities towards the design of vaccines against VBDs. Having said that, novel composite formulations combining both vector saliva components and pathogen-derived antigens represent another path towards the design of more elaborated and efficient vaccines against numerous VBDs.

\section{Abbreviations}

AD: atopic dermatitis; AMPs: antimicrobial peptides; An.: Anopheles; CSP: circumsporozoite protein; DCs: dendritic cells; DENV: Dengue virus; DTH: delayed type hypersensitivity; FceRI: IgE bind to high-affinity receptors; HRF: histamine releasing factor; Lu.: Lutzomyia; MAX: maxadilan; MCs: mast cells; MDA5: melanoma differentiation-associated gene 5; NO: nitric oxide; NTDs: neglected tropical diseases; P.: Phlebotomus;
PBMCs: peripheral blood mononuclear cell; PGE2: prostaglandin E2; PKR: protein kinase R; PRRs: pattern recognition receptors; RIG-I: retinoic-acid-inducible gene I; RVF: Rift Valley fever; SCID: severe combined immunodeficiency mice; SGE: salivary gland extracts; TLRs: toll like receptors; TSLP: thymic stromal lymphopoietin; VBDs: vector-borne diseases; VL: visceral leishmaniasis; WHO: World Health Organization.

\section{Acknowledgments}

We thank the CEPIA (Centre d'élevage, de production et d'infection des anopheles, Institut Pasteur, Paris) for providing infected Anopheles mosquitoes.

\section{Availability of data and materials}

Not applicable

\section{Funding}

This work was supported by grants from Institut Pasteur, and from the French Parasitology consortium ParaFrap to SM. CDG was supported by a post-doctoral fellowship from the Helmut Horten Foundation, Agno, Switzerland.

\section{Competing interests}

The authors declare that they have no competing interests.

\section{Authors' contributions}

CDG and SM wrote and revised the manuscript. All authors read and approved the final manuscript.

\section{Ethics approval}

Not applicable.

\section{Consent for publication}

Not applicable.

\section{References}

1. Murray CJL, Lopez AD. The Global Burden of Disease: A Comprehensive Assessment of Mortality and Disability from Diseases. Geneva, Switzerland: Worlf Health Organization, 1996.

2. World Health Organization. World health statistics 2019: monitoring health for the SDGs, sustainable development goals. 2019.

3. Taylor LH, Latham SM, Woolhouse ME. Risk factors for human disease emergence. Philos Trans R Soc Lond B Biol Sci. 2001 Jul 29;356(1411):983-9.

4. Daszak P, Cunningham AA, Hyatt AD. Anthropogenic environmental change and the emergence of infectious diseases in wildlife. Acta Trop. $2001 \mathrm{Feb} ; 78(2): 103-16$.

5. Wang LF, Crameri G. Emerging zoonotic viral diseases. Rev Sci Tech. 2014 Aug;33(2):569-81.

6. Stephen C, Artsob H, Bowie WR, Drebot M, Fraser E, Leighton T, et al. Perspectives on emerging zoonotic disease research and capacity building in Canada. Can J Infect Dis Med Microbiol, 2004 Nov;15(6):339-44. 
7. World Health Organization. A global brief on vector-borne diseases. Organizaton WH, editor. Geneva, Switzerland: WHO Press. 2014.

8. Campbell LP, Luther C, Moo-Llanes D, Ramsey JM, Danis-Lozano R, Peterson AT. Climate change influences on global distributions of dengue and chikungunya virus vectors. Philos Trans R Soc Lond B Biol Sci. 2015 Apr 5;370(1665):20140135.

9. Kraemer MU, Sinka ME, Duda KA, Mylne AQ, Shearer FM, Barker CM, et al. The global distribution of the arbovirus vectors Aedes aegypti and Ae. albopictus. Elife. 2015 Jun 30;4:e08347.

10. Cox J, Mota J, Sukupolvi-Petty S, Diamond MS, Rico-Hesse R. Mosquito bite delivery of dengue virus enhances immunogenicity and pathogenesis in humanized mice. J Virol. 2012 Jul;86(14):7637-49.

11. Schneider BS, Soong L, Zeidner NS, Higgs S. Aedes aegypti salivary gland extracts modulate anti-viral and $\mathrm{TH} 1 / \mathrm{TH} 2$ cytokine responses to sindbis virus infection. Viral Immunol, 2004;17(4):565-73.

12. Schneider BS, Soong L, Girard YA, Campbell G, Mason P, Higgs S. Potentiation of West Nile encephalitis by mosquito feeding. Viral Immunol, 2006 Mar 22;19(1):74-82.

13. Edwards JF, Higgs S, Beaty BJ. Mosquito feeding-induced enhancement of Cache Valley Virus (Bunyaviridae) infection in mice. J Med Entomol. 1998 May;35(3):261-5.

14. Limesand KH, Higgs S, Pearson LD, Beaty BJ. Potentiation of vesicular stomatitis New Jersey virus infection in mice by mosquito saliva. Parasite Immunol. 2000 Sep;22(9):461-7.

15. Lestinova T, Rohousova I, Sima M, Oliveira Cl, Volf P. Insights into the sand fly saliva: Blood-feeding and immune interactions between sand flies, hosts, and Leishmania. PLoS Negl Trop Dis. 2017 Jul 13;11(7):e0005600.

16. Schneider BS, Mathieu C, Peronet R, Mécheri S. Anopheles stephensi saliva enhances progression of cerebral malaria in a murine model. Vector Borne Zoonotic Dis. 2011 Apr;11(4):423-32.

17. Aitken TH, Downs WG, Shope RE. Aedes aegypti strain fitness for yellow fever virus transmission. Am J Trop Med Hyg. 1977 Sep;26(5 Pt 1):985-9.

18. Gubler DJ, Nalim S, Tan R, Saipan H, Sulianti Saroso J. Variation in susceptibility to oral infection with dengue viruses among geographic strains of Aedes aegypti. Am J Trop Med Hyg. 1979 Nov;28(6):1045-52.

19. Hardy JL, Houk EJ, Kramer LD, Reeves WC. Intrinsic factors affecting vector competence of mosquitoes for arboviruses. Annu Rev Entomol. 1983;28:229-62.

20. Severson DW, Behura SK. Genome investigations of vector competence in Aedes aegypti to inform novel arbovirus disease control approaches. Insects. 2016 Oct 30;7(4):58.

21. Cohuet A, Harris C, Robert V, Fontenille D. Evolutionary forces on Anopheles: what makes a malaria vector? Trends Parasitol. 2010 Mar;26(3):130-6.

22. Turell MJ, Linthicum KJ, Patrican LA, Davies FG, Kairo A, Bailey CL. Vector competence of selected African mosquito (Diptera: Culicidae) species for Rift Valley fever virus. J Med Entomol, 2008 Jan;45(1):102-8.

23. Moore CG, Cline BL, Ruiz-Tibén E, Lee D, Romney-Joseph H, RiveraCorrea E. Aedes aegypti in Puerto Rico: environmental determinants of larval abundance and relation to dengue virus transmission. Am J Trop Med Hyg. 1978 Nov;27(6):1225-31.

24. Chretien JP, Anyamba A, Small J, Britch S, Sanchez JL, Halbach AC, et al. Global climate anomalies and potential infectious disease risks: 20142015. PLoS Curr. 2015 Jan 26;7.

25. Dohm DJ, O'Guinn ML, Turell MJ. Effect of environmental temperature on the ability of Culex pipiens (Diptera: Culicidae) to transmit West Nile virus. J Med Entomol. 2002 Jan;39(1):221-5.

26. Ezeakacha NF, Yee DA. The role of temperature in affecting carry-over effects and larval competition in the globally invasive mosquito Aedes albopictus. Parasit Vectors. 2019;12(1):123.

27. Thomas SM, Obermayr U, Fischer D, Kreyling J, Beierkuhnlein C. Lowtemperature threshold for egg survival of a post-diapause and non-diapause European aedine strain, Aedes albopictus (Diptera: Culicidae). Parasit Vectors. 2012 May 23;5:100.
28. Carrington LB, Seifert SN, Armijos MV, Lambrechts L, Scott TW. Reduction of Aedes aegypti vector competence for dengue virus under large temperature fluctuations. Am J Trop Med Hyg. 2013 Apr 3;88(4):689-97.

29. Oo TT, Storch V, Madon MB, Becker N. Factors influencing the seasonal abundance of Aedes (Stegomyia) aegypti and the control strategy of dengue and dengue haemorrhagic fever in Thanlyin Township, Yangon City, Myanmar. Trop Biomed. 2011 Aug;28(2):302-11.

30. James AA, Rossignol PA. Mosquito salivary glands: Parasitological and molecular aspects. Parasitol Today, 1991;7(10):267-71.

31. Titus RG, Ribeiro JM. The role of vector saliva in transmission of arthropod-borne disease. Parasitol Today. 1990 May;6(5):157-60.

32. Ribeiro JM. Role of saliva in blood-feeding by arthropods. Annu Rev Entomol. 1987;32:463-78.

33. Belkaid Y, Kamhawi S, Modi G, Valenzuela J, Noben-Trauth N, Rowton $E$, et al. Development of a natural model of cutaneous leishmaniasis: powerful effects of vector saliva and saliva preexposure on the long-term outcome of Leishmania major infection in the mouse ear dermis. J Exp Med. 1998 Nov 16;188(10):1941-53.

34. Ribeiro JM, Francischetti IM. Role of arthropod saliva in blood feeding: sialome and post-sialome perspectives. Annu Rev Entomol. 2003;48:73-88.

35. Cantillo JF, Fernández-Caldas E, Puerta L. Immunological aspects of the immune response induced by mosquito allergens. Int Arch Allergy Immunol. 2014;165(4):271-82.

36. Depinay N, Hacini F, Beghdadi W, Peronet R, Mecheri S. Mast celldependent down-regulation of antigen-specific immune responses by mosquito bites. J Immunol, 2006 Apr 1;176(7):4141-6.

37. Hajnicka V, Vancova I, Kocakova P, Slovak M, Gasperik J, Slavikova M, et al. Manipulation of host cytokine network by ticks: a potential gateway for pathogen transmission. Parasitology. 2005 Mar;130(Pt 3):333-42.

38. Schneider BS, Higgs S. The enhancement of arbovirus transmission and disease by mosquito saliva is associated with modulation of the host immune response. Trans R Soc Trop Med Hyg, 2008 May;102(5):400-8.

39. de Moura TR, Oliveira F, Novais FO, Miranda JC, Clarencio J, Follador I, et al. Enhanced Leishmania braziliensis infection following pre-exposure to sandfly saliva. PLoS Negl Trop Dis. 2007 Nov;1(2):e84.

40. Mesquita RD, Carneiro AB, Bafica A, Gazos-Lopes F, Takiya CM, Souto-Padron T, et al. Trypanosoma cruzi infection is enhanced by vector saliva through immunosuppressant mechanisms mediated by lysophosphatidylcholine. Infect Immun. 2008 Dec;76(12):5543-52.

41. Volf $P$, Tesarová $P$, Nohýnkova EN. Salivary proteins and glycoproteins in phlebotomine sandflies of various species, sex and age. Med Vet Entomol. 2000 Sep;14(3):251-6.

42. Volf P, Rohousová I. Species-specific antigens in salivary glands of phlebotomine sandflies. Parasitology. 2001 Jan;122(Pt 1):37-41.

43. Warburg A, Saraiva E, Lanzaro GC, Titus RG, Neva F. Saliva of Lutzomyia longipalpis sibling species differs in its composition and capacity to enhance leishmaniasis. Philos Trans R Soc Lond B Biol Sci. 1994 Jul 29;345(1312):22330.

44. Lanzaro GC, Lopes AH, Ribeiro JM, Shoemaker CB, Warburg A, Soares $M$, et al. Variation in the salivary peptide, maxadilan, from species in the Lutzomyia longipalpis complex. Insect Mol Biol. 1999 May;8(2):267-75.

45. Ramalho-Ortigão M, Coutinho-Abreu IV, Balbino VQ, Figueiredo CA, Mukbel Jr R, Dayem H, et al. Phlebotomus papatasi SP15: mRNA expression variability and amino acid sequence polymorphisms of field populations. Parasit Vectors. 2015 May 29;8:298.

46. Ribeiro JM, Vachereau A, Modi GB, Tesh RB. A novel vasodilatory peptide from the salivary glands of the sand fly Lutzomyia longipalpis. Science. 1989 Jan 13;243(4888):212-4.

47. Ribeiro JM, Katz O, Pannell LK, Waitumbi J, Warburg A. Salivary glands of the sand fly Phlebotomus papatasi contain pharmacologically active amounts of adenosine and 5'-AMP. J Exp Biol. 1999 Jun;202(Pt 11):1551-9.

48. Ribeiro JM, Modi G. The salivary adenosine/AMP content of Phlebotomus argentipes Annandale and Brunetti, the main vector of human kala-azar. J Parasitol. 2001 Aug;87(4):915-7. 
49. Charlab R, Valenzuela JG, Rowton ED, Ribeiro JM. Toward an understanding of the biochemical and pharmacological complexity of the saliva of a hematophagous sand fly Lutzomyia longipalpis. Proc Natl Acad Sci U S A. 1999 Dez 21;96(26):15155-60.

50. Hamasaki R, Kato H, Terayama $Y$, Iwata $H$, Valenzuela JG. Functional characterization of a salivary apyrase from the sand fly, Phlebotomus duboscqi, a vector of Leishmania major. J Insect Physiol. 2009 Nov;55(11):1044-9.

51. Valenzuela JG, Belkaid Y, Rowton E, Ribeiro JM. The salivary apyrase of the blood-sucking sand fly Phlebotomus papatasi belongs to the novel Cimex family of apyrases. J Exp Biol. 2001 Jan;204(Pt 2):229-37.

52. Cavalcante RR, Pereira MH, Gontijo NF. Anti-complement activity in the saliva of phlebotomine sand flies and other haematophagous insects. Parasitology. 2003 Jul;127(Pt 1):87-93.

53. Zeidner NS, Higgs S, Happ CM, Beaty BJ, Miller BR. Mosquito feeding modulates Th1 and Th2 cytokines in flavivirus susceptible mice: an effect mimicked by injection of sialokinins, but not demonstrated in flavivirus resistant mice. Parasite Immunol. 1999 Jan;21(1):35-44.

54. Pingen M, Bryden SR, Pondeville E, Schnettler E, Kohl A, Merits A, et al. Host inflammatory response to mosquito bites enhances the severity of arbovirus infection. Immunity. 2016 Jun 21;44(6):1455-69.

55. Vogt MB, Lahon A, Arya RP, Kneubehl AR, Spencer Clinton JL, Paust S, et al. Mosquito saliva alone has profound effects on the human immune system. PLoS Negl Trop Dis. 2018 May 17;12(5):e0006439.

56. Barros MS, Gomes E, Gueroni DI, Ramos AD, Mirotti L, Florsheim $\mathrm{E}$, et al. Exposure to Aedes aegypti bites induces a mixed-type allergic response following salivary antigens challenge in mice. PLoS One. 2016 May;11(5):e0155454.

57. Manning JE, Morens DM, Kamhawi S, Valenzuela JG, Memoli M. Mosquito Saliva: The Hope for a Universal Arbovirus Vaccine? J Infect Dis. 2018 Jun 5;218(1):7-15.

58. Esnault S, Rosenthal LA, Wang DS, Malter JS. Thymic stromal lymphopoietin (TSLP) as a bridge between infection and atopy. Int J Clin Exp Pathol. 2008 Jan 1;1(4):325-30.

59. Soumelis V, Reche PA, Kanzler H, Yuan W, Edward G, Homey B, et al. Human epithelial cells trigger dendritic cell mediated allergic inflammation by producing TSLP. Nat Immunol. 2002 Jul;3(7):673-80.

60. Elenkov IJ, Webster E, Papanicolaou DA, Fleisher TA, Chrousos GP, Wilder RL. Histamine potently suppresses human IL-12 and stimulates IL-10 production via H2 receptors. J Immunol. 1998 Sep 1;161(5):2586-93.

61. Ferguson TA, Dube P, Griffith TS. Regulation of contact hypersensitivity by interleukin 10. J Exp Med. 1994; May 1;179(5):1597-604.

62. Grimbaldeston MA, Nakae S, Kalesnikoff J, Tsai M, Galli SJ. Mast cellderived interleukin 10 limits skin pathology in contact dermatitis and chronic irradiation with ultraviolet B. Nat Immunol. 2007;8(10):1095-104.

63. Brummer-Korvenkontio H, Lappalainen P, Reunala T, Palosuo T. Detection of mosquito saliva-specific $\lg$ E and $\operatorname{lgG} 4$ antibodies by immunoblotting. J Allergy Clin Immunol. 1994;93(3):551-5.

64. Chen YL, Simons FE, Peng Z. A mouse model of mosquito allergy for study of antigen-specific IgE and IgG subclass responses, lymphocyte proliferation, and IL-4 and IFN-gamma production. Int Arch Allergy Immunol. 1998 Aug;116(4):269-77.

65. French FE, West AS. Skin reaction specificity of guinea pig immediate hypersensivity to bites of four mosquito species. J Parasitol. 1971 Apr;57(2):396-400.

66. Reunala T, Brummer-Korvenkontio H, Rasanen L, Francois G, Palosuo T. Passive transfer of cutaneous mosquito-bite hypersensitivity by IgE anti-saliva antibodies. J Allergy Clin Immunol. 1994 Nov;94(5):902-6.

67. Oka K, Ohtaki N, Yasuhara T, Nakajima T. A study of mosquito salivary gland components and their effects on man. J Dermatol. 1989 Dec;16(6):469-74.

68. Peng Z, Yang M, Simons FE. Immunologic mechanisms in mosquito allergy: correlation of skin reactions with specific $\lg E$ and $\lg G$ antibodies and lymphocyte proliferation response to mosquito antigens. Ann Allergy Asthma Immunol. 1996 Sep;77(3):238-44.

69. Reunala T, Lappalainen P, Brummer-Korvenkontio H, Coulie P, Palosuo T. Cutaneous reactivity to mosquito bites: effect of cetirizine and development of anti-mosquito antibodies. Clin Exp Allergy. 1991 Sep;21(5):617-22.
70. Demeure CE, Brahimi K, Hacini F, Marchand F, Peronet R, Huerre M, et al. Anopheles mosquito bites activate cutaneous mast cells leading to a local inflammatory response and lymph node hyperplasia. J Immunol. 2005 Apr 1;174(7):3932-40.

71. Biedermann T, Kneilling M, Mailhammer R, Maier K, Sander CA, Kollias G, et al. Mast cells control neutrophil recruitment during $T$ cellmediated delayed-type hypersensitivity reactions through tumor necrosis factor and macrophage inflammatory protein 2. J Exp Med. 2000 Nov 20;192(10):1441-52.

72. Malaviya R, Ikeda T, Ross E, Abraham SN. Mast cell modulation of neutrophil influx and bacterial clearance at sites of infection through TNF-alpha. Nature. 1996 May 2;381(6577):77-80.

73. Enk A.H, Angeloni VL, Udey MC, Katz SI. Inhibition of Langerhans cell antigen-presenting function by IL-10. A role for IL-10 in induction of tolerance. J Immunol. 1993 Sep 1;151(5):2390-8.

74. Brady MT, MacDonald AJ, Rowan AG, Mills KH. Hepatitis C virus nonstructural protein 4 suppresses Th1 responses by stimulating IL-10 production from monocytes. Eur J Immunol, 2003 Dec;33(12):3448-57.

75. Macatonia SE, Doherty TM, Knight SC, O'Garra A. Differential effect of IL-10 on dendritic cell-induced T cell proliferation and IFN-gamma production. J Immunol. 1993 May 1;150(9):3755-65.

76. Ejrnaes M, Filippi CM, Martinic MM, Ling EM, Togher LM, Crotty S, von Herrath MG. Resolution of a chronic viral infection after interleukin-10 receptor blockade. J Exp Med. 2006 Oct 30;203(11):2461-72.

77. Teixeira CR, Teixeira MJ, Gomes RB, Santos CS, Andrade BB, RaffaeleNetto I, et al. Saliva from Lutzomyia longipalpis induces CC chemokine ligand 2/monocyte chemoattractant protein-1 expression and macrophage recruitment. J Immunol. 2005 Dec 15;175(12):8346-53.

78. Mbow ML, Bleyenberg JA, Hall LR, Titus RG. Phlebotomus papatasi sand fly salivary gland lysate down-regulates a Th1, but up-regulates a Th2, response in mice infected with Leishmania major. J Immunol. $1998 \mathrm{Nov}$ 15;161(10):5571-7.

79. Waitumbi J. Warburg A. Phlebotomus papatasi saliva inhibits protein phosphatase activity and nitric oxide production by murine macrophages. Infect Immun. 1998 Apr;66(4):1534-7.

80. Dong Z, Yang X, Xie K, Juang SH, Llansa N, Fidler IJ. Activation of inducible nitric oxide synthase gene in murine macrophages requires protein phosphatases 1 and 2A activities. J Leukoc Biol. 1995 Dec;58(6):725-32.

81. Abdeladhim M, Ben Ahmed M, Marzouki S, Belhadj Hmida N, Boussoffara $\mathrm{T}$, Belhaj Hamida $\mathrm{N}$, et al. Human cellular immune response to the saliva of Phlebotomus papatasi is mediated by IL-10-producing CD8+ T cells and Th1-polarized CD4+ lymphocytes. PLoS Negl Trop Dis. 2011 Oct;5(10):e1345.

82. Costa DJ, Favali C, Clarêncio J, Afonso L, Conceição V, Miranda JC, et al. Lutzomyia longipalpis salivary gland homogenate impairs cytokine production and costimulatory molecule expression on human monocytes and dendritic cells. Infect Immun. 2004 Mar;72(3):1298-305.

83. Prates DB, Araújo-Santos T, Luz NF, Andrade BB, França-Costa J, Afonso $\mathrm{L}$, et al. Lutzomyia longipalpis saliva drives apoptosis and enhances parasite burden in neutrophils. J Leukoc Biol. 2011 Sep;90(3):575-82.

84. Rogers KA, Titus RG. Immunomodulatory effects of Maxadilan and Phlebotomus papatasi sand fly salivary gland lysates on human primary in vitro immune responses. Parasite Immunol. 2003 Mar;25(3):127-34.

85. Soares MB, Titus RG, Shoemaker CB, David JR, Bozza M. The vasoactive peptide maxadilan from sand fly saliva inhibits TNF-alpha and induces IL-6 by mouse macrophages through interaction with the pituitary adenylate cyclase-activating polypeptide (PACAP) receptor. J Immunol. 1998 Feb 15;160(4):1811-6.

86. Brodie TM, Smith MC, Morris RV, Titus RG. Immunomodulatory effects of the Lutzomyia longipalpis salivary gland protein maxadilan on mouse macrophages. Infect Immun. 2007;75(5):2359-65.

87. Wheat WH, Pauken KE, Morris RV, Titus RG. Lutzomyia longipalpis salivary peptide maxadilan alters murine dendritic cell expression of CD80/86, CCR7, and cytokine secretion and reprograms dendritic cell-mediated cytokine release from cultures containing allogeneic T cells. J Immunol. 2008 Jun 15;180(12):8286-98. 
88. Carregaro V, Valenzuela JG, Cunha TM, Verri WA Jr, Grespan R, Matsumura $G$, et al. Phlebotomine salivas inhibit immune inflammationinduced neutrophil migration via an autocrine DC-derived PGE2/IL-10 sequential pathway. J Leukoc Biol. 2008 Jul;84(1):104-14.

89. Araújo-Santos T, Prates DB, Andrade BB, Nascimento DO, Clarêncio J, Entringer PF, et al. Lutzomyia longipalpis saliva triggers lipid body formation and prostaglandin $\mathrm{E}_{2}$ production in murine macrophages. PLoS Negl Trop Dis. 2010 Nov 2;4(11):e873.

90. Ockenfels B, Michael E, McDowell MA. Meta-analysis of the effects of insect vector saliva on host immune responses and infection of vectortransmitted pathogens: a focus on leishmaniasis. PLoS Negl Trop Dis. 2014 Oct 2;8(10):e3197.

91. Kamhawi S, Belkaid Y, Modi G, Rowton E, Sacks D. Protection against cutaneous leishmaniasis resulting from bites of uninfected sand flies. Science. 2000 Nov 17;290(5495):1351-4.

92. Donovan MJ, Messmore AS, Scrafford DA, Sacks DL, Kamhawi S, McDowell MA. Uninfected mosquito bites confer protection against infection with malaria parasites. Infect Immun. 2007 May;75(5):2523-30.

93. Rogers ME, Sizova OV, Ferguson MA, Nikolaev AV, Bates PA. Synthetic glycovaccine protects against the bite of leishmania-infected sand flies. J Infect Dis. 2006 Aug 15;194(4):512-8.

94. World Health Organization. World Malaria Report. 2017.

95. Hay SI, Guerra CA, Tatem AJ, Atkinson PM, Snow RW. Urbanization, malaria transmission and disease burden in Africa. Nat Rev Microbiol. 2005 Jan;3(1):81-90.

96. Hay SI, Smith DL, Snow RW. Measuring malaria endemicity from intense to interrupted transmission. Lancet Infect Dis. 2008 Jun;8(6):369-78.

97. Ashley EA, Dhorda M, Fairhurst RM, Amaratunga C, Lim P, Suon S, et al. Spread of artemisinin resistance in Plasmodium falciparum malaria. $N$ Engl J Med. 2014 Jul 31;371(5):411-23.

98. Packard RM. The origins of antimalarial-drug resistance. $\mathrm{N}$ Engl J Med. 2014 Jul 31;371(5):397-9.

99. Brown AW. The insecticide-resistance problem: a review of developments in 1956 and 1957. Bull World Health Organ. 1958;18(3):309-21.

100. Harbach RE. The classification of genus Anopheles (Diptera: Culicidae): a working hypothesis of phylogenetic relationships. Bull Entomol Res. 2004 Dec;94(6):537-53.

101. Meigen JW. Systematische Beschreibung der Bekannten Europaischen Zweiflügeligen Insekten. Forstmann, Aachen. p. 11-12. 1818.

102. Harbach RE. The Culicidae (Diptera): a review of taxonomy, classification and phylogeny*. Zootaxa. 2007;1668(1668):591-638.

103. Paupy CB, Makanga B, Ollomo B, Rahola N, Durand P, Magnus J, et al. Anopheles moucheti and Anopheles vinckei are candidate vectors of ape Plasmodium parasites, including Plasmodium praefalciparum in Gabon. PLoS One. 2013;8(2):e57294.

104. Sougoufara S, Doucouré S, Backé Sembéne PM, Harry M, Sokhna C. Challenges for malaria vector control in sub-Saharan Africa: Resistance and behavioral adaptations in Anopheles populations. J Vector Borne Dis. 2017 Jan-Mar;54(1):4-15.

105. Mitchell AJ, Hansen AM, Hee L, Ball HJ, Potter SM, Walker JC, et al. Early cytokine production is associated with protection from murine cerebral malaria. Infect Immun. 2005 Sep;73(9):5645-53.

106. Schneider BS, Mathieu C, Peronet R, Mecheri S. Anopheles stephensi saliva enhances progression of cerebral malaria in a murine model. Vector Borne Zoonotic Dis. 2011 Apr;11(4):423-32.

107. Chakravarty S, Cockburn IA, Kuk S, Overstreet MG, Sacci JB, Zavala F. CD8+ T lymphocytes protective against malaria liver stages are primed in skin-draining lymph nodes. Nat Med. 2007 Sep;13(9):1035-41.

108. Wu Y, Wang QH, Zheng L, Feng H, Liu J, Ma SH, et al. Plasmodium yoelii: distinct $\mathrm{CD} 4(+) \mathrm{CD} 25(+)$ regulatory $\mathrm{T}$ cell responses during the early stages of infection in susceptible and resistant mice. Exp Parasitol. 2007 Mar;115(3):301-4.

109. Fontaine A, Diouf I, Bakkali N, Missé D, Pagès F, Fusai T, et al. Implication of haematophagous arthropod salivary proteins in host-vector interactions. Parasit Vectors. 2011;4:187.
110. Mendes-Sousa AF, Queiroz DC, Vale VF, Ribeiro JM, Valenzuela JG, Gontijo NF, et al. An Inhibitor of the Alternative Pathway of Complement in Saliva of New World Anopheline Mosquitoes. J Immunol. 2016 Jul 15;197(2):599-610.

111. Mejia P, Diez-Silva M, Kamena F, Lu F, Fernandes SM, Seeberger PH, et al. Human C1-Inhibitor Suppresses Malaria Parasite Invasion and Cytoadhesion via Binding to Parasite Glycosylphosphatidylinositol and Host Cell Receptors. J Infect Dis. 2016 Jan 1;213(1):80-9.

112. Lawaly R, Konate L, Marrama L, Dia I, Diallo D, Diene Sarr F, et al. Impact of mosquito bites on asexual parasite density and gametocyte prevalence in asymptomatic chronic Plasmodium falciparum infections and correlation with IgE and IgG titers. Infect Immun. 2012 Jun;80(6):2240-6.

113. Barber $M$, Olinger $M$. Studies on malaria in southern Nigeria. Ann Trop Med Parasitol. 1931 Oct 5;25: 461-501.

114. Miller MJ. Observations on the natural history of malaria in the semiresistant West African. Trans R Soc Trop Med Hyg. 1958;52(2):152-68.

115. Rosenberg R, Andre RG, Ketrangsee S. Seasonal fluctuation of Plasmodium falciparum gametocytaemia. Trans R Soc Trop Med Hyg. 1990 JanFeb;84(1):29-33.

116. Herrant M, Loucoubar C, Bassene H, Goncalves B, Boufkhed S, Diene Sarr $\mathrm{F}$, et al. Asthma and atopic dermatitis are associated with increased risk of clinical Plasmodium falciparum malaria. BMJ Open. 2013 Jul 24;3(7):e002835.

117. Gould E, Pettersson J, Higgs S, Charrel R, de Lamballerie X. Emerging arboviruses: Why today? One Health. 2017 Jul 1;4:1-13.

118. Huang YS, Higgs S, Vanlandingham DL. Arbovirus-Mosquito Vector-Host Interactions and the Impact on Transmission and Disease Pathogenesis of Arboviruses. Front Microbiol. 2019;10:22.

119. Ryman KD, Klimstra WB. Host responses to alphavirus infection. Immunol Rev. 2008 Oct;225:27-45.

120. Conway MJ, Colpitts TM, Fikrig E. Role of the Vector in Arbovirus Transmission. Annu Rev Virol. 2014 Nov;1(1):71-88.

121. Le Coupanec A, Babin D, Fiette L, Jouvion G, Ave P, Misse D, et al. Aedes mosquito saliva modulates Rift Valley fever virus pathogenicity. PLoS Negl Trop Dis. 2013 Jun 13;7(6):e2237.

122. Agarwal A, Joshi G, Nagar DP, Sharma AK, Sukumaran D, Pant SC, Parida MM, et al. Mosquito saliva induced cutaneous events augment Chikungunya virus replication and disease progression. Infect Genet Evol. 2016;40:126-35.

123. Orozco S, Schmid MA, Parameswaran P, Lachica R, Henn MR, Beatty $R$, et al. Characterization of a model of lethal dengue virus 2 infection in C57BL/6 mice deficient in the alpha/beta interferon receptor. J Gen Virol. 2012 Oct;93(Pt 10):2152-7.

124. Schmid MA, Glasner DR, Shah S, Michlmayr D, Kramer LD, Harris E. Mosquito Saliva Increases Endothelial Permeability in the Skin, Immune Cell Migration, and Dengue Pathogenesis during Antibody-Dependent Enhancement. PLoS Pathog. 2016 Jun 16;12(6):e1005676.

125. Surasombatpattana P, Hamel R, Patramool S, Luplertlop N, Thomas F, Desprès $P$, et al. Dengue virus replication in infected human keratinocytes leads to activation of antiviral innate immune responses. Infect Genet Evol. 2011 Oct;11(7):1664-73.

126. Surasombatpattana P, Patramool S, Luplertlop N, Yssel H, Missé D. Aedes aegypti saliva enhances dengue virus infection of human keratinocytes by suppressing innate immune responses. J Invest Dermatol. 2012 Aug;132(8):2103-5.

127. Surasombatpattana $P$, Ekchariyawat $P$, Hamel R, Patramool S, Thongrungkiat $\mathrm{S}$, Denizot $\mathrm{M}$, et al. Aedes aegypti saliva contains a prominent $34-\mathrm{kDa}$ protein that strongly enhances dengue virus replication in human keratinocytes. J Invest Dermatol. 2014 Jan;134(1):281-4.

128. Fenwick $A$. The global burden of neglected tropical diseases. Public Health. 2012 Mar;126(3):233-6.

129. Desjeux P. Leishmaniasis: current situation and new perspectives. Comp Immunol Microbiol Infect Dis. 2004 Sep;27(5):305-18.

130. World Health Organization. Leishmaniasis. 2018.

131. Ready PD. Biology of phlebotomine sand flies as vectors of disease agents. Annu Rev Entomol. 2013;58:227-50. 
132. Young DG, Duncan MA. Guide to the identification and geographic distribution of Lutzomyia sand flies in Mexico, the West Indies, Central and South America (Diptera: Psychodidae). Gainesville (FL): Associated Publishers/American Entomological Institute; 1994. 881 p.

133. Galati EAB. Phylogenetic systematics of phlebotominae (diptera, psychodidae) with emphasis on american groups. Bol Dir Malariol San Amb. 1995.

134. Shimabukuro PHF, Galati EAB. Lista de espécies de Phlebotominae (Diptera, Psychodidae) do Estado de São Paulo, Brasil, com comentários sobre sua distribuição geográfica. Biota Neotrop. 2011 Jan-Dec;11:685-704.

135. Theodos CM, Ribeiro JM, Titus RG. Analysis of enhancing effect of sand fly saliva on Leishmania infection in mice. Infect Immun. 1991 May;59(5):1592-8.

136. Titus RG, Ribeiro JM. Salivary gland lysates from the sand fly Lutzomyia longipalpis enhance Leishmania infectivity. Science. 1988 Mar 11;239(4845):1306-8.

137. Norsworthy NB, Sun J, Elnaiem D, Lanzaro G, Soong L. Sand fly saliva enhances Leishmania amazonensis infection by modulating interleukin-10 production. Infect Immun. 2004 Mar;72(3):1240-7.

138. Silva F, Gomes R, Prates D, Miranda JC, Andrade B, Barral-Netto M, et al. Inflammatory cell infiltration and high antibody production in BALB/C mice caused by natural exposure to Lutzomyia longipalpis bites. Am J Trop Med Hyg. 2005 Jan;72(1):94-8.

139. Monteiro MC, Lima HC, Souza AA, Titus RG, Romão PR, Cunha FQ. Effect of Lutzomyia longipalpis salivary gland extracts on leukocyte migration induced by Leishmania major. Am J Trop Med Hyg. 2007 Jan;76(1):88-94.

140. Pimenta PF, Dos Santos MA, De Souza W. Fine structure and cytochemistry of the interaction between Leishmania mexicana amazonensis and rat neutrophils and eosinophils. J Submicrosc Cytol. 1987 Jul;19(3):387-95.

141. van Zandbergen G, Klinger M, Mueller A, Dannenberg S, Gebert A, Solbach $W$, et al. Cutting edge: neutrophil granulocyte serves as a vector for Leishmania entry into macrophages. J Immunol. 2004 Dec 1;173(11):6521-5.

142. Morris RV, Shoemaker CB, David JR, Lanzaro GC, Titus RG. Sandfly maxadilan exacerbates infection with Leishmania major and vaccinating against it protects against L. major infection. J Immunol. 2001 Nov 1;167(9):5226-30.

143. Samuelson J, Lerner E, Tesh R, Titus RG. A mouse model of Leishmania braziliensis braziliensis infection produced by coinjection with sand fly saliva. J Exp Med. 1991 Jan 1;173(1):49-54.

144. Bezerra HS, Teixeira MJ. Effect of Lutzomyia whitmani (Diptera: Psychodidae) salivary gland lysates on Leishmania (Viannia) braziliensis infection in BALB/c mice. Mem Inst Oswaldo Cruz. 2001 Apr;96(3):349-51.

145. Rohoušová I, Hostomská J, Vlková M, Kobets T, Lipoldová M, Volf P. The protective effect against Leishmania infection conferred by sand fly bites is limited to short-term exposure. Int J Parasitol. 2011 Apr;41(5):481-5.

146. Chaudhury S, Ockenhouse CF, Regules JA, Dutta S, Wallqvist A, Jongert $E$, et al. The biological function of antibodies induced by the RTS,S/AS01 malaria vaccine candidate is determined by their fine specificity. Malar J. 2016 May 31;15:301.

147. Kaslow DC, Biernaux S. Toward a first landmark on the Malaria Vaccine Technology Roadmap. Vaccine. 2015 Dec 22;33(52):7425-32.

148. Oliveira F, Rowton E, Aslan H, Gomes R, Castrovinci PA, Alvarenga PH, et al. A sand fly salivary protein vaccine shows efficacy against vectortransmitted cutaneous leishmaniasis in nonhuman primates. Sci Transl Med. 2015 Jun 3;7(290):290ra90.

149. Lestinova T, Vlkova M, Votypka J, Volf P, Rohousova I. Phlebotomus papatasi exposure cross-protects mice against Leishmania major co-inoculated with Phlebotomus duboscqi salivary gland homogenate. Acta Trop. 2015 Apr;144:9-18.

150. Gomes R, Teixeira C, Teixeira MJ, Oliveira F, Menezes MJ, Silva C, et al. Immunity to a salivary protein of a sand fly vector protects against the fatal outcome of visceral leishmaniasis in a hamster model. Proc Natl Acad Sci U S A. 2008 Jun 3;105(22):7845-50.

151. Collin N, Gomes R, Teixeira C, Cheng L, Laughinghouse A, Ward JM, et al. Sand fly salivary proteins induce strong cellular immunity in a natural reservoir of visceral leishmaniasis with adverse consequences for Leishmania. PLoS Pathog. 2009 May;5(5):e1000441.
152. Wheat WH, Arthun EN, Spencer JS, Regan DP, Titus RG, Dow SW. Immunization against full-length protein and peptides from the Lutzomyia longipalpis sand fly salivary component maxadilan protects against Leishmania major infection in a murine model. Vaccine. 2017 Dec 4;35(48 Pt B):6611-9.

153. Aguiar-Soares RD, Roatt BM, Ker HG, Moreira N, Mathias FA, Cardoso JM, et al. LBSapSal-vaccinated dogs exhibit increased circulating T-lymphocyte subsets $\left(\mathrm{CD}^{+}\right.$and $\left.\mathrm{CD}^{+}\right)$as well as a reduction of parasitism after challenge with Leishmania infantum plus salivary gland of Lutzomyia longipalpis. Parasit Vectors. 2014 Feb 7;7:61.

154. Zahedifard F, Gholami E, Taheri T, Taslimi Y, Doustdari F, Seyed N, et al. Enhanced protective efficacy of nonpathogenic recombinant leishmania tarentolae expressing cysteine proteinases combined with a sand fly salivary antigen. PLoS Negl Trop Dis. 2014 Mar 27;8(3):e2751.

155. da Silva RA, Tavares NM, Costa D, Pitombo M, Barbosa L, Fukutani K, et al. Lutzomyia longipalpis salivary protein protects hamsters against visceral leishmaniasis. Acta Trop. 2011 Dec;120(3):185-90.

156. Reed SG, Coler RN, Mondal D, Kamhawi S, Valenzuela JG. Leishmania vaccine development: exploiting the host-vector-parasite interface. Expert Rev Vaccines. 2016;15(1):81-90

157. Marie A, Holzmuller P, Tchioffo MT, Rossignol M, Demettre E, Seveno M, et al. Anopheles gambiae salivary protein expression modulated by wild Plasmodium falciparum infection: highlighting of new antigenic peptides as candidates of An. gambiae bites. Parasit Vectors. 2014 Dec 20;7:599.

158. Zocevic A, Carmi-Leroy A, Sautereau J, d'Alayer J, Lenormand P, Rousselle JC, et al. New markers in Anopheles gambiae salivary glands after Plasmodium berghei infection. Vector Borne Zoonotic Dis. 2013 Feb;13(2):119-27.

159. Calvo E, Sanchez-Vargas I, Kotsyfakis M, Favreau AJ, Barbian KD, Pham $V M$, et al. The salivary gland transcriptome of the eastern tree hole mosquito, Ochlerotatus triseriatus. J Med Entomol. 2010 May;47(3):376-86.

160. VanBuskirk KM, O’Neill MT, De La Vega P, Maier AG, Krzych U, Williams J, et al. Preerythrocytic, live-attenuated Plasmodium falciparum vaccine candidates by design. Proc Natl Acad Sci U S A. 2009 Aug 4;106(31): 13004-9.

161. Vaughan AM, Mikolajczak SA, Wilson EM, Grompe M, Kaushansky A, Camargo N, et al. Complete Plasmodium falciparum liver-stage development in liver-chimeric mice. J Clin Invest. 2012 Oct;122(10):3618-28.

162. Kebaier C, Voza T, Vanderberg J. Neither mosquito saliva nor immunity to saliva has a detectable effect on the infectivity of Plasmodium sporozoites injected into mice. Infect Immun. 2010 Jan;78(1):545-51.

163. Pollock T, Leitao R, Galan-Rodriguez C, Wong KA, Rodriguez A. Daily Plasmodium yoelii infective mosquito bites do not generate protection or suppress previous immunity against the liver stage. Malar J. 2011 Apr 18;10:97.

164. Fontaine A, Pascual A, Orlandi-Pradines E, Diouf I, Remoué F, Pagès F, et al. Relationship between exposure to vector bites and antibody responses to mosquito salivary gland extracts. PLoS One. 2011;6(12):e29107.

165. Poinsignon A, Cornelie S, Mestres-Simon M, Lanfrancotti A, Rossignol $M$, Boulanger $D$, et al. Novel peptide marker corresponding to salivary protein gSG6 potentially identifies exposure to Anopheles bites. PLoS One. 2008 Jun 25;3(6):e2472.

166. Remoue F, Cisse B, Ba F, Sokhna C, Herve JP, Boulanger D, et al. Evaluation of the antibody response to Anopheles salivary antigens as a potential marker of risk of malaria. Trans R Soc Trop Med Hyg. 2006 Apr;100(4): 363-70.

167. Waitayakul A, Somsri S, Sattabongkot J, Looareesuwan S, Cui L, Udomsangpetch R. Natural human humoral response to salivary gland proteins of Anopheles mosquitoes in Thailand. Acta Trop. 2006 Apr;98(1):66-73.

168. Oliveira F, Traoré B, Gomes R, Faye O, Gilmore DC, Keita S, et al. Delayedtype hypersensitivity to sand fly saliva in humans from a leishmaniasisendemic area of Mali is Th1-mediated and persists to midlife. J Invest Dermatol. 2013 Feb;133(2):452-9.

169. Doucoure S, Mouchet F, Cournil A, Le Goff G, Cornelie S, Roca Y, et al Human antibody response to Aedes aegypti saliva in an urban population 
in Bolivia: a new biomarker of exposure to Dengue vector bites. Am J Trop Med Hyg. 2012 Sep 5;87(3):504-10.

170. Londono-Renteria B, Cardenas JC, Cardenas LD, Christofferson RC, Chisenhall DM, Wesson DM, et al. Use of anti-Aedes aegypti salivary extract antibody concentration to correlate risk of vector exposure and dengue transmission risk in Colombia. PLoS One. 2013 Dec 2;8(12):e81211.
171. Manning JE, Oliveira F, Coutinho-Abreu IV, Herbert S, Meneses C, Kamhawi $S$, et al. Safety and immunogenicity of a mosquito saliva peptidebased vaccine: a randomised, placebo-controlled, double-blind, phase 1 trial. Lancet. 2020 Jun 27;395(10242):1998-2007. 